\title{
GOVERNANÇA DA ÁGUA: COMPARAÇÃO ENTRE A REGIÃO HIDROGRÁFICA DO CENTRO DE PORTUGAL E A BACIA HIDROGRÁFICA DO RIO APODI- MOSSORÓ/RN NO BRASIL
}

Resumo: Este trabalho objetiva comparar a forma de gestão dos recursos hídricos de Portugal e do Brasil. Para isso, a metodologia inclui: revisão sistemática de literatura, investigação documental sobre a legislação das águas e, estudo de campo sobre participação social na gestão das águas. Apurou-se avanço na legislação dos recursos hídricos e diferenças jurídicas em ambos os países. Estas distinções refletem diretamente na participação pública da gestão dos recursos hídricos, verificando-se que em Portugal os Conselhos de Região Hidrográfica são informativos e consultivos, enquanto no Brasil os Comitês de Bacia Hidrográfica são negociadores e deliberativos. Portanto, as referidas leis precisam de aperfeiçoamento para a sua efetivação com eficácia, com verificação dos seus aspectos positivos e negativos.

Palavras-chave: Direito ambiental comparado. Políticas públicas de recursos hídricos. Participação social. Gestão democrática.

\section{WATER GOVERNANCE: COMPARISON BETWEEN THE HYDROGRAPHIC REGION OF CENTRAL PORTUGAL AND THE APODI-MOSSORÓ/RN RIVER WATERSHED IN BRAZIL}

Abstract: This work aims to compare the way water resources are managed in Portugal and Brazil. For this, the methodology includes: systematic literature review, documentary research on water legislation and field study on social participation in water management. Progress has been made in the legislation of water resources and legal differences in both countries. These distinctions directly reflect the public participation of water resource management, verifying that in Portugal the Hydrographic Region Councils are informative and consultative, while in Brazil the Hydrographic Basin Committees are negotiators and deliberatives. Therefore, these laws need improvement for their effectiveness effectively, with verification of their positive and negative aspects.

Keywords: Compared environmental law. Public water resources policies. Social participation. Democratic management.

\section{GOBIERNO DEL AGUA: COMPARISON ENTRE LA REGION HIDROGRAFICA CENTRAL DE PORTUGAL Y EL BASIN DE RIVER APODI-MOSSOR/RN EN BRASIL}

Resumen: Este trabajo tiene como objetivo comparar la forma en que se gestionan los recursos hídricos en Portugal y Brasil. Para ello, la metodología incluye: revisión sistemática de la literatura, investigación documental sobre legislación hídrica y

\footnotetext{
1 Universidade Federal Rural do Semiárido (UFERSA), Departamento de Engenharias e Tecnologia Pau dos Ferros, Brasil, jorge.filho@ufersa.edu.br, https://orcid.org/0000-0002-2730-6929

2 Universidade de Coimbra (UC), Departamento de Geografia e Turismo, Coimbra, Portugal, luciogeo@ci.uc.pt, https://orcid.org/0000-0003-0086-7862
} 
estudio de campo sobre la participación social en la gestión del agua. Se han realizado progresos en la legislación sobre los recursos hídricos y en las diferencias jurídicas en ambos países. Estas distinciones reflejan directamente la participación pública de la gestión de los recursos hídricos, verificando que en Portugal los Consejos de la Región Hidrográfica sean informativos y consultivos, mientras que en Brasil los Comités de Cuenca Hidrográfica son negociadores y deliberativos. Por lo tanto, estas leyes necesitan mejoras para su eficacia de manera efectiva, con la verificación de sus aspectos positivos y negativos.

Palabras clave: Legislación ambiental comparada. Políticas públicas de recursos hídricos. Participación social. Gestión democrática.

\section{Introdução}

A água é um dos compostos de maior distribuição na crosta terrestre, sendo um elemento essencial e indispensável à manutenção da vida (BRAGA et al., 2005), tornando-se responsável por manter a biodiversidade nos sistemas terrestre, aquático e atmosférico (TUNDISI, 2011). Com isso, é utilizada de forma múltipla, em usos consuntivos (irrigação, abastecimento humano, setor industrial e uso animal) e usos não consuntivos (geração de energia elétrica, navegação, diluição de efluentes, pesca, preservação da flora e fauna e recreação), que provocam processos de poluição de origem natural e antrópica (urbana, agropastoril e industrial), decorrendo a partir de fontes pontuais e não pontuais (difusas) (DERÍSIO, 2017).

Nesta perspectiva, os processos de poluição hídrica geram consequências sistêmicas, a saber: econômica (desvalorização dos recursos hídricos e maior necessidade de capital financeiro para controle ambiental); social (vulnerabilidade de populações e atividades tradicionais); ambiental (alteração da sua qualidade e quantidade); de saúde pública (surgimento de vetores de doenças) e, de modo mais geral, a deterioração dos recursos (alteração ecológica) (DERíSIO, 2017).

A partir deste panorama de crise de paradigma, medidas de controle ambiental são desenvolvidas, sendo classificadas em estruturais (obras de engenharia) e não estruturais (políticas ambientais) (DERísıO, 2017). Assim, observa-se que o processo de resolução dos conflitos hídricos potencializa a interação de usuários variados, do poder público e da sociedade em geral, e com isso o viés de expandir o espaço de tomada de decisão, visto que a complexidade ambiental contemporânea precisa ser compreendida de forma holística e interdisciplinar.

Desta forma, os Estados estruturaram em seu arcabouço jurídico, dispositivos de participação popular para aperfeiçoar o uso dos recursos hídricos. Em Portugal, 
aprovou-se a Lei da Água, que transpõe para a ordem jurídica nacional a Directiva Qualidade de Água - DQA n.ำ 2000/60/CE, do Parlamento Europeu e do Conselho, de 23 de Outubro, sendo atualizada pela Lei n.. 44/2017 de 19 de Junho. No Brasil, estabelece a Política Nacional de Recursos Hídricos - PNRH pela Lei 9.433/1997.

A partir deste contexto, a governança da água em Portugal se estabeleceu com evolução ao longo dos anos, sendo enaltecido por Pato (2007) que a partir de finais do século XIX que se começam a definir os contornos essenciais de uma política da água à escala nacional, sendo inicialmente uma fase de origem e consolidação (de 1884 até 1928) com paradigma de obras públicas hidráulica; em seguida uma etapa de tradição hidráulica (entre 1929 até 1974) com princípios de produção de energia e; finalmente a transição para uma visão ambiental (entre 1975 até o presente) com os paradigmas ambiental, preocupações sociais e, integração de políticas.

No caso específico do Brasil, a governança da água tem passando por reformas, permitindo a participação da sociedade e, reconhecimento da bacia hidrográfica como unidade de planejamento e gestão, tornando-se essencialmente preditiva, com a finalidade de antecipar processos e fenômenos (TUNDISI, 2016). Para Magalhães Junior (2010) as bases da reforma legal e institucional do sistema de gestão das águas no Brasil ocorre com uma Gestão descentralizada e participativa através de Comitês de bacia. Nesta linha de pensamento, Gusmão e Pavão (2019) afirma que estes órgãos colegiados negociam e deliberam sobre a gestão de águas, utilizando-se de instrumentos técnicos de gestão, de negociação de conflitos e da promoção dos usos múltiplos da água, para resolução de conflitos. Sendo assim, a governança está centrada na noção de poder social que media as relações entre Estado e sociedade civil, como espaço para a construção de alianças e cooperação (JACOBI, 2009). Portanto, a gestão participativa é crescente no país, buscando a resolução de problemas, porém ainda há muito que avançar na obtenção de consenso, tanto na forma, quanto na qualidade de suas decisões (RIBEIRO, 2009).

Diante dos modelos de Gestão dos Recursos Hídricos - GRH em Portugal e no Brasil, pode-se inferir que estes foram instituídos a partir de contextos distintos e específicos, possibilitando a constituição da Administrações de Região Hidrográfica - ARH e Comitês de Bacias Hidrográficas - $\mathrm{CBH}$, respectivamente. É importante ressaltar que estas instituições representam importantes papéis em cada realidade, 
sendo a portuguesa mais influenciada por instituições externas (Comunidade Europeia) e a brasileira mais interativa com outros setores (atores sociais).

No sentido de compreender a complexidade da $\mathrm{GRH}$, este artigo pretende realizar um estudo comparativo entre o Conselho de Região Hidrográfica - $\mathrm{CRH}$ do Centro de Portugal e o $\mathrm{CBH}$ do Rio Apodi-Mossoró/RN, no Brasil, acerca das similaridades no planejamento, mobilização e participação na gestão da água.

Estudos dos modelos de GRH em Portugal e no Brasil vêm sendo realizados por diferentes autores, a saber: em Portugal por Albufeira (1998); INAG (2001); ARH Centro (2011); Schimdt e Ferreira (2013); Zucco e Costa (2014); Ferreira (2017); no Brasil através de Amorim, Ribeiro e Braga (2016); Barros, Paiva e Cisneiros (2017); Bolson e Haonat (2016); Caldas (2019); Cerqueira et al. (2016); Costa (2017); Fadul, Vitória e Cerqueira (2017); Feil, Strasburg e Spilki (2017); Lopes e Neves (2017); Luz (2017); Martins (2015); Silva, Herrero e Borges (2017); Trindade, Scheibe e Ribeiro (2018); Vasconcelos et al. (2016); e conjuntamente em Portugal e no Brasil por meio de Agra Filho e Ramos (2015); Alovisi Junior e Berezuk (2012); Amorim (2015); Campos e Francalanza (2010); Casarin (2017); Costa et al. (2011); Ferreira e Debeus (2019); Magalhães et al. (2011); Ribeiro (2016); Ribeiro, Ribeiro e Varanda (2016); Silva et al. (2018); Silva, Ferreira e Pompêo (2013); Travassos (2013); Vasconcelos et al. (2011) e Young e Sedoura (2019). Entretanto, estes estudos não desenvolveram uma forma sistemática de comparação dos modelos de GRH.

Face a esta contextualização, estudos comparativos sobre modelos de GRH em Portugal e Brasil precisam ser desenvolvidos para compreender as relações entre seus elementos e desenvolver diretrizes de aperfeiçoamento destes mecanismos.

Assim, este trabalho tem como objetivo geral comparar o $\mathrm{CRH}$ do Centro/Portugal e o CBH do Rio Apodi/Mossoró/Brasil sobre as políticas públicas da água. Para isso, definiram-se como objetivos específicos: descrever o histórico de formação do $\mathrm{CRH}$ do Centro e do $\mathrm{CBH}$ do Rio Apodi/Mossoró; caracterizar o $\mathrm{CRH}$ do Centro e o $\mathrm{CBH}$ do Rio Apodi/Mossoró; analisar a atuação do $\mathrm{CRH}$ do Centro e do $\mathrm{CBH}$ do Rio Apodi/Mossoró; investigar a participação dos membros do $\mathrm{CRH}$ do Centro e do $\mathrm{CBH}$ do Rio Apodi/Mossoró e; identificar os desafios e dilemas da operação do $\mathrm{CRH}$ do Centro e do $\mathrm{CBH}$ do Rio Apodi/Mossoró. 


\section{Metodologia}

A condução desta pesquisa pautou-se na classificação da caracterização da área de estudo e determinação dos procedimentos metodológicos.

\section{Classificação da pesquisa}

A pesquisa tem uma abordagem dedutiva (MARCONI; LAKATOS, 2017), partindo do entendimento de que o fenômeno que respeita aos conflitos dos usos dos recursos hídricos da atualidade, propiciou modelos de gestão que envolvem diversos atores e são contextualizados em cada território. Com isso, estrutura-se o estudo em cinco dimensões, a saber: objetivos, procedimentos técnicos, método de abordagem, métodos de procedimento e tipologia (MARCONI; LAKATOS, 2017).

A pesquisa classifica-se quanto aos seus objetivos, conforme Gil (2019), em exploratória, a qual tem como função desenvolver, esclarecer e modificar conceitos e ideias para formular problemas mais precisos e construir hipóteses, pelo que proporciona uma visão geral do fato; descritiva, que tem a finalidade de descrever as características de determinada população ou fenômeno e/ou o estabelecimento de relação entre variáveis; e explicativa, que tem como propósito identificar fatores que determinam ou contribuem para a ocorrência dos fenômenos. Nesta perspectiva, este estudo busca explorar as formas de $\mathrm{GRH}$, descrever os seus processos de formulação e explicar a comparação destes modelos de gestão entre Portugal e Brasil.

O trabalho desenvolveu-se com procedimentos que possibilitam a estruturação em: pesquisa bibliográfica, que oferece ao pesquisador uma gama de fenômenos muito mais amplo em relação àquela que poderia pesquisar diretamente; pesquisa documental, que se refere à coleta de informações secundárias e sem tratamento analítico; estudo de caso, que se caracteriza por sustentar pesquisas profundas, com um ou poucos objetos, adquirindo conhecimento amplo e detalhado; e de campo, que consistem em dados primários (GIL, 2019). Desta forma, procurouse realizar um estudo de caso sobre os modelos de $\mathrm{GRH}$ adotados no $\mathrm{CRH}$ do Centro/Portugal e no CBH do Rio Apodi/Mossoró/Brasil, já que Yin (2005) delimita esta abordagem como forma de compreensão em que se investiga um fenômeno atual e específica.

Ao delimitar a abordagem temática do estudo, definiu-se a forma de condução que será realizada pelo método de abordagem indutivo fundamentado na 
experiência e na observação que leva a algo novo e fenomenológico, que consiste na descrição direta da experiência tal como ela é, sem nenhuma consideração acerca de sua gênese e das explicações causais que os especialistas podem dar (GIL, 2019). Com isto, esta pesquisa observa o $\mathrm{CRH}$ (Portugal) e $\mathrm{CBH}$ (Brasil) para descrever as semelhanças e diferenças entre estes dispositivos legais de gestão.

A viabilização deste estudo se dá por adotar métodos, compreendidos por Marconi e Lakatos (2017) como meios técnicos para garantir a objetividade no estudo, sendo adotados: o método monográfico, que visa investigar qualquer caso que se estude em profundidade e que pode ser considerado representativo; 0 método observacional, que possibilita o mais alto grau de precisão através da observação de algo que acontece ou já aconteceu; o método histórico, que consiste em investigar acontecimentos, processos e instituições do passado; e o método comparativo, que realiza comparações com a finalidade de verificar similitudes e explicar divergências. Para isso, pretende-se observar e caracterizar as formas de $\mathrm{GRH}$ em Portugal $(\mathrm{CRH})$ e Brasil $(\mathrm{CBH})$, o histórico evolutivo destes órgãos, para comparação entre eles.

Para tanto, estudo adota a forma qualitativa para expor os resultados da $\mathrm{GRH}$ em Portugal e no Brasil (MARCONI; LAKATOS, 2017).

\section{Caracterização da área de estudo}

A comparação entre a governança das águas neste estudo ocorre em dois contextos distintos, já que o Brasil, é um país emergente na América Latina com grande dimensão continental, diversidade ecológica e recursos hídricos e, com uma gestão influenciada por fatores internos; enquanto Portugal, um país desenvolvido integrante da União Europeia, com pequena dimensão territorial, com importantes recursos hídricos costeiros e continentais e, com uma gestão influenciada por fatores externos. Apesar destas realidades antagônicas, a abrangência da Área da Região Hidrográfica Centro - 4 (localizada totalmente em Portugal, sendo a maior genuinamente deste país) e, da Bacia Hidrográfica do Rio Apodi-Mossoró (localizada totalmente no Rio Grande do Norte, sendo a maior genuinamente deste estado) ocorre em específicos territórios, com base em suas respectivas características geopolíticas, permite comparar os modelos de gestão, já que estão inseridas em duas unidades políticas e administrativas autônomas, baseada na divisão do território para fins político-administrativos destes países. 
Reforça esta linha de pensamento de viabilidade de comparação, o percurso na qual a governança das águas destes país encontram-se, visto que a partir das da Constituição da República Portuguesa (1976) e Constituição Federal do Brasil (1988) a matéria ambiental ganhou autonomia, com a criação de capítulo específico, sendo $66 . .^{\circ}$ e $225 .-$, respectivamente, bem como a criação de leis específicas dos recursos hídricos em Portugal (DQA) e Brasil (PNRH) e, as influências das legislações superiores.

Nesse sentido, a comparação entre a governança das águas em dois contextos distintos permitirá determinar realidades bastante específicas em função do espaço e do tempo em que foram desenvolvidas e, os resultados atingidos não se encerram em si, uma vez que a temática investigada em Portugal e no Brasil, ainda conhecerá alterações futuras, já que se encontra intimamente ligado ao momento do desenvolvimento da economia e da sociedade. Acrescenta ainda que as possíveis modificações nas legislações nacionais e internacionais que abordam o tema, uma vez que as alterações propostas e implementadas por estes instrumentos podem transformar significativamente a aplicação dos modelos de gestão dos recursos hídricos.

Isto posto, a escolha de Portugal e Brasil, se deu baseado nos argumentos defendidos por Tonelotto e Crozatti (2017) que afirmam que são dois países com proximidade cultural e histórica, dado que a estrutura do setor público brasileiro teve suas origens nas estruturas existentes em Portugal e ainda hoje, conservam similaridades entre si.

Em Portugal investigou-se a Região Hidrográfica Centro - 4, Figura 01, que é formada pelas bacias dos rios Vouga, Mondego e Lis, além de pequenas bacias costeiras, com uma área total de $12.144 \mathrm{~km} 2$, incluindo as respectivas águas subterrâneas e águas costeiras adjacentes (APA, 2020).

O rio Vouga nasce na serra da Lapa, a cerca de $930 \mathrm{~m}$ de altitude e percorre $148 \mathrm{~km}$ até desaguar na Barra de Aveiro, tendo como principais afluentes o Águeda e o seu afluente, o Cértima, o Caster e o Antuã, na parte Norte, e o Boco e a ribeira da Corujeira, a Sul. A sua bacia hidrográfica estabelece-se na zona de transição entre o Norte e o Sul de Portugal, sendo limitada pelos paralelos 40'15' e 4057' de latitude Norte e os meridianos $7^{\circ} 33^{\prime}$ e $8^{\circ} 48^{\prime}$ de longitude Oeste e é confinada ao sul pela Serra do Buçaco, que a separa da bacia do rio Mondego, e a norte pelas serras de Leomil, Montemuro, Lapa e Serra de Freita, que a separam da bacia do rio Douro (APA, 2020). 
O rio Mondego é o maior rio integralmente em território português e nasce na Serra da Estrela, a $1.525 \mathrm{~m}$ de altitude, em uma pequena fonte designada por "O Mondeguinho". Percorre $258 \mathrm{~km}$ até desaguar no Oceano Atlântico junto à Figueira da Foz, contando com os rios afluentes Dão, Alva, Ceira e Arunca. A bacia hidrográfica deste rio, a segunda maior bacia integralmente nacional, situa-se na região centro de Portugal, especificamente entre as bacias dos rios Vouga e Douro a Oeste e a Norte, e as bacias dos rios Tejo e Lis a Sul, nos paralelos 39 $46^{\circ}$ e $40^{\circ} 48^{\prime}$ de latitude Norte e os meridianos $7^{\circ} 14^{\prime}$ e $8^{\circ} 52^{\prime}$ de longitude Oeste, apresentando assim uma área da bacia hidrográfica de $6.645 \mathrm{~km}^{2}$, com forma grosseiramente retangular (APA, 2020).

O rio Lis nasce na povoação de Fontes, no concelho de Leiria e deságua no Oceano Atlântico, a norte de Praia da Vieira, com cerca de $40 \mathrm{~km}$ e com os rios afluentes Fora e a ribeira da Caranguejeira, na margem direita, e Lena e a ribeira do Rio Seco, na margem esquerda. A bacia hidrográfica deste rio é uma bacia costeira com uma área de $945 \mathrm{~km}^{2}$ e está confinada a leste pela bacia do rio Tejo e a sul pela bacia do Alcoa (APA, 2020).

No Brasil investigou-se a Bacia Hidrográfica do Rio Apodi-Mossoró (Figura 02), que tem uma área de $14.276,00 \mathrm{~km}^{2}$, configurando-se a segunda maior bacia do Estado do Rio Grande do Norte, com a concentração de 618 açudes, totalizando um volume de acumulação de $469.714 .600 \mathrm{~m}^{3}$ de água, o equivalente a, respectivamente, $27,4 \%$ e $10,7 \%$ dos totais de açudes e volumes acumulados no Estado (Instituto de Gestão das Águas do Rio Grande do Norte - IGARN, 2017).

Figura 01- ARH do Centro, Portugal

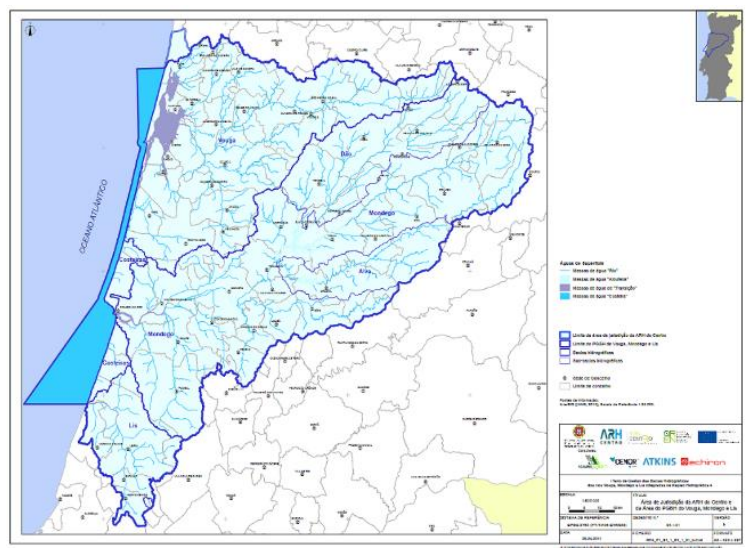

Fonte: ARH do Centro (2011).
Figura 02- BH do Rio Apodi-Mossoró, Brasil

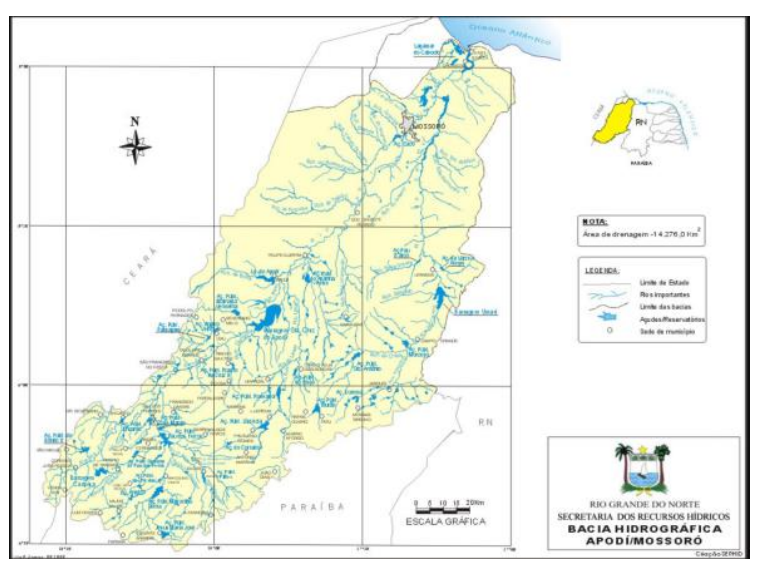

Fonte: SEMARH (2020). 


\section{Procedimentos metodológicos}

Os procedimentos metodológicos desta investigação foram divididos nas seguintes etapas: i) definição da temática de estudo; ii) levantamento teórico da temática; iii) definição dos instrumentos de pesquisa; iv) obtenção, organização e tratamento dos dados e v) análise dos dados.

Etapa I - Definição da temática do estudo: este estudo faz parte de um projeto que visa a análise comparativa da GRH no Brasil e em Portugal, tomando como estudo de caso o $\mathrm{CRH}$ do Centro/Portugal e do $\mathrm{CBH}$ do Rio Apodi/Mossoró/Brasil. Desta forma, a delimitação da temática do estudo se deu com a definição do histórico de formação, caracterização, análise de atuação, comparação da participação dos membros e identificação dos desafios e dilemas destes modelos de governança.

Etapa II - Levantamento teórico da temática: com a definição da temática do estudo desenvolveu-se o seu levantamento teórico, através da Revisão Sistemática da Literatura - RSL, em que Morandi e Camargo (2015) definem a sequência que o pesquisador precisa entender e seguir para que o trabalho de revisão seja bem feito, tendo em vista a minimização dos problemas que podem atrapalhar o relatório final, sendo composta pelas etapas: a) fontes de busca da temática, b) estratégias para o viés da pesquisa, c) avaliação dos estudos da literatura para RSL, d) ferramentas a serem utilizadas na síntese dos resultados e e) a apresentação do estudo.

A partir dessa sequência, definiram-se métodos na RSL sobre GRH de Portugal e Brasil: i) seleção da ferramenta de busca dos artigos científicos (para além do conhecimento pessoal, definiu-se como motor de busca o Google Acadêmico); ii) definição de descritores para a busca dos artigos científicos (comparação da atuação de Comitê de bacias em Portugal e no Brasil); iii) busca na literatura com primeiro filtro da delimitação temporal dos artigos entre 2010 a 2019 (14.200 resultados); iv) busca na literatura com segundo filtro com abordagem da temática: conflitos, comitês, gestão, gerenciamento, governança, legislação, planejamento, plano e política no título dos artigos entre 2010 a 2019 (30 resultados); v) avaliação da qualidade metodológica (constatação de metodologias revisadas por pares); vi) metanálise dos dados (variáveis: autores, base de dados, tipos de produção, método científico, profissão do pesquisador, grupo de pesquisa, temática, principais resultados, região do estudo, nome do local de publicação, ano do estudo); vii) avaliação da qualidade das evidências (confronto dos principais 
resultados com as legislações citadas) e viii) redação final dos resultados. Para tanto, foram analisadas 30 pesquisas sobre a $\mathrm{GRH}$.

Etapa III - Definição dos instrumentos de pesquisa: as técnicas de coletas de dados compreendem-se como um conjunto de preceitos ou processos de que se serve uma ciência, bem como, as competências para usar esses preceitos ou normas, na obtenção de seus propósitos (MARCONI; LAKATOS, 2017). Neste percurso metodológico os procedimentos técnicos utilizados foram: pesquisa bibliográfica (GRH em Portugal e no Brasil); levantamento documental (Histórico do $\mathrm{CRH}$ do Centro/Portugal e do $\mathrm{CBH}$ do Rio Apodi/Mossoró/Brasil) e entrevistas semiestruturadas com os tópicos de caracterização do órgão, atuação do órgão, mobilização e comunicação do órgão, participação dos membros do órgão, atuação do representante do órgão e planejamento do órgão (aos representantes).

Etapa IV - Obtenção, organização e tratamento dos dados: a obtenção dos dados do $\mathrm{CRH}$ do Centro/Portugal ocorreu por entrevista junto ao seu representante legal no dia 15 de fevereiro de 2020, enquanto os dados do $\mathrm{CBH}$ do Rio Apodi/Mossoró/Brasil ocorreu junto ao seu diretor no dia 05 de janeiro de 2020, onde os mesmos foram organizados em textos e quadros por instituição, a partir da ordem da estrutura do roteiro de entrevista e tratados para a compreensão da GRH).

Etapa V - Análise dos dados: por fim, os dados foram apresentados seguindo a ordem de discussão: caracterização do $\mathrm{CRH}$ do Centro/Portugal, descrição do $\mathrm{CBH}$ Apodi-Mossoró/RN/Brasil e comparativo de atuação entre o $\mathrm{CRH}$ do Centro/Portugal e o $\mathrm{CBH}$ do rio Apodi-Mossoró/RN/Brasil, tornando viável a discussão e análise dos dados e a comparação com trabalhos da revisão sistemática.

\section{Resultados e Discussão}

\section{O CRH do Centro/Portugal}

Os CRH's são órgãos consultivos da APA, em que estão os ministérios, outros organismos da Administração Pública, os municípios diretamente interessados e as entidades representativas dos principais utilizadores relacionados com o uso consuntivo e não consuntivo da água na respectiva bacia hidrográfica, bem como as organizações técnicas, científicas e não-governamentais representativas dos usos da água na bacia hidrográfica (APA, 2020). Sendo assim, definiu-se a jurisdição territorial dos $\mathrm{CRH}$, que coincidem respectivamente com as 
áreas territoriais das $\mathrm{ARH}$, do Norte, do Centro, do Tejo e Oeste, do Alentejo e do

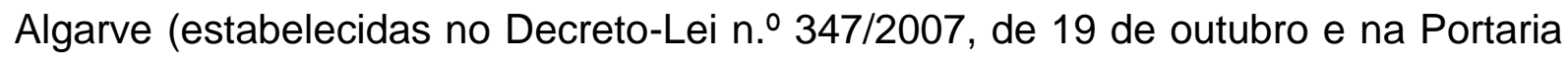
n..$^{108 / 2013}$, de 15 de março).

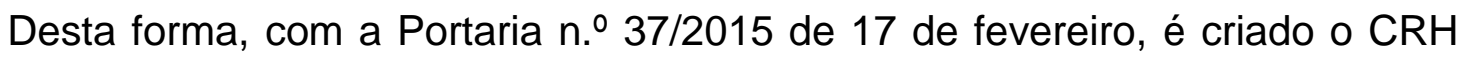
do Centro, que apresenta as seguintes competências: a) acompanhar e participar da elaboração dos planos de gestão de bacia hidrográfica e dos planos específicos de gestão das águas; b) participar na elaboração dos programas de medidas para operacionalização e implementação futuras; c) promover e acompanhar a definição de procedimentos e a produção de informação relativamente à avaliação da execução dos programas de medidas para os recursos hídricos; d) acompanhar, participar e partilhar programas e resultados de monitorização e de avaliação do estado das massas de água; e) assegurar que o planeamento e a gestão de recursos hídricos constituem um contributo relevante para o desenvolvimento sustentável da bacia hidrográfica; f) emitir parecer sobre questões relativas a metas e procedimentos para a utilização eficiente dos recursos hídricos; g) contribuir para que as questões associadas à adaptação e às alterações climáticas sejam ponderadas; h) promover a formação e a disseminação pública da informação relevante para que os objetivos dos planos de gestão da bacia hidrográfica sejam atingidos; i) acompanhar e participar nos programas e medidas que a APA submeta à sua consideração e j) emitir parecer.

A partir destas competências, estabeleceu-se a composição do $\mathrm{CRH}$ do Centro, integrando os membros: a) o presidente, designado pelo membro do Governo responsável pela área do ambiente; b) o secretário, designado pelo presidente da APA e c) Os vogais que representam as entidades da Administração Pública Central, os municípios, as entidades gestoras de serviços de águas de nível municipal ou multimunicipal, os utilizadores relacionados com o uso consuntivo e não consuntivo da água e dos setores da atividade econômica e individualidades de mérito, prestígio acadêmico ou profissional com incidência na área territorial do $\mathrm{CRH}$.

Com isso, o $\mathrm{CRH}$ do Centro, entrou em operação com a primeira reunião para a aprovação do seu regulamento de, que continha as normas: a) a direção do $\mathrm{CRH}$ do Centro cabe ao presidente que é substituído nas suas faltas e impedimentos pelo diretor da $\mathrm{ARH}$ do Centro ou por vogal; b) o $\mathrm{CRH}$ do Centro pode reunir em primeira convocatória desde que se encontre presente a maioria do número legal dos seus membros com direito a voto; c) quando não seja possível obter o quórum previsto no 
número anterior o $\mathrm{CRH}$ do Centro pode se reunir, em segunda convocatória, com um terço dos membros com direito a voto; d) as deliberações do $\mathrm{CRH}$ do Centro são tomadas por maioria simples dos membros presentes, exercendo o presidente voto de qualidade; e) cada entidade do $\mathrm{CRH}$ do Centro dispõe de um voto independentemente do número de representantes; f) a participação nas reuniões do $\mathrm{CRH}$ do Centro, bem como a votação, pode ser realizada através de conferência telefônica ou videoconferência; g) o presidente do $\mathrm{CRH}$ do Centro por sua iniciativa ou a requerimento dos membros do $\mathrm{CRH}$, pode convidar ou autorizar a participação nas reuniões deste órgão consultivo, de técnicos, peritos ou representantes de entidades com interesse para os temas a discutir, sem direito a voto; h) o $\mathrm{CRH}$ do Centro se reúne ordinariamente três vezes por ano e, extraordinariamente, sempre que convocado pelo seu presidente, ou por solicitação (um terço dos seus membros); i) os membros do $\mathrm{CRH}$ do Centro não usufruem de qualquer remuneração nem complemento remuneratório pelo exercício desta atividade; j) são supletivamente aplicáveis ao $\mathrm{CRH}$ do Centro as regras do Código do Procedimento Administrativo.

Nesta perspectiva de funcionamento, o $\mathrm{CRH}$ do Centro tem as estruturas consultivas voltadas para: a) criação de conselhos consultivos em seu âmbito regional; b) os conselhos consultivos de âmbito regional são presididos pelo presidente do $\mathrm{CRH}$ do Centro; c) o $\mathrm{CRH}$ do Centro pode ainda deliberar a constituição de grupos especializados, com composição e mandato definido, para a elaboração de pareceres, relatórios, estudos ou informações destinados a apoiar a respectiva atividade.

Com isso, para viabilizar a operação do $\mathrm{CRH}$ do Centro, estabeleceram-se os seus membros, a partir do poder público, iniciativa privada e sociedade civil (Quadro 01), onde a composição refletiu a especificidade da referida Região Hidrográfica, a transversalidade da água face aos vários setores da economia e do ambiente, a imprescindível interação da administração pública e da sociedade civil na gestão da água e, ainda, a aplicação do conhecimento técnico científico.

Quadro 01- Composição do CRH do Centro.

a) um representante da Comissão de Coordenação e Desenvolvimento Regional do Centro;

b) um representante do Instituto da Conservação da Natureza e das Florestas;

c) um representante da Entidade Reguladora dos Serviços de Águas e Resíduos

d) um representante da Direção-Geral de Energia e Geologia;

e) um representante da Direção-Geral de Agricultura e Desenvolvimento Rural;

f) um representante da Direção-Geral de Recursos Naturais, Segurança e Serviços Marítimos

g) um representante da Direção-Geral das Atividades Econômicas

h) um representante do Turismo de Portugal;

i) um representante da Autoridade Nacional de Proteção Civil;

j) um representante do Agência para a Competitividade e Inovação;

k) um representante da Direção Regional de Agricultura e Pescas do Centro;

l) um representante da Administração Regional de Saúde do Centro;

m) um representante do Departamento Marítimo do Centro da Direção-Geral da Autoridade Marítima; 

\begin{tabular}{|l|}
\hline n) um representante da Equipa de Proteção da Natureza e Ambiente; \\
\hline o) um representante do Instituto Português do Mar e da Atmosfera; \\
\hline p) um representante do Turismo do Centro de Portugal; \\
\hline q) um representante da Administração do Porto de Aveiro S. A.; \\
\hline r) um representante da Administração do Porto da Figueira da Foz S. A.; \\
\hline s) até seis representantes de municípios na área territorial do CRH do Centro; \\
\hline t) um representante das entidades gestoras de serviços de águas de nível multimunicipal; \\
\hline u) um representante das entidades gestoras de serviços de águas de nível municipal; \\
\hline v) um representante das associações de utilizadores de recursos hídricos da área territorial do CRH do Centro; \\
\hline x) um representante das associações de regantes da área territorial do CRH do Centro; \\
\hline w) um representante das associações de agricultores da área territorial do CRH do Centro; \\
\hline y) até dois representantes das associações de pescas e aquicultura da área territorial do CRH do Centro; \\
\hline z) um representante da Confederação de Turismo de Portugal; \\
\hline aa) um representante das indústrias do setor agroindustrial e agropecuário; \\
\hline bb) até dois representantes das indústrias dos sectores considerados relevantes na área do CRH do Centro; \\
\hline cc) um representante dos produtores de energia hidroelétrica; \\
\hline dd) um representante de ordens profissionais de relevo nas áreas do ambiente e dos recursos hídricos; \\
\hline ee) até dois representantes de instituições de ensino superior, investigação, desenvolvimento e inovação; \\
\hline ff) até dois representantes de associações científicas e técnicas nas áreas do ambiente e dos recursos hídricos; \\
\hline gg) até dois representantes de organizações não governamentais de ambiente e dos recursos hídricos; \\
\hline hh) um representante de núcleos empresariais na área territorial abrangida pelo CRH do Centro; \\
\hline ii) até cinco individualidades de reconhecido mérito, prestígio académico ou profissional e trabalho de relevo desenvolvido na área dos \\
recursos hídricos, com particular incidência na área territorial do CRH do Centro. \\
\hline Fonte: APA (2020).
\end{tabular}

Fonte: APA (2020).

Diante do apresentado, constata-se que o Plano de Gestão da Região hidrográfica - PGRH do Centro, é composto por dois volumes: I Enquadramento e aspetos gerais) e II (Caracterização e diagnóstico), para o período de 2016/2021. Desta forma, ressalta-se que as principais atuações deste planejamento se referem as ações de articular com órgãos superiores, reunir membros, elaborar planos, minutas e relatórios, debater a temática de forma regional, articular eventos, intervir em debates técnicos, orientar entidades, acompanhar usos e mediar com órgãos afins da temática, dentre outras demandas referentes ao centro português.

\section{O CBH Apodi-Mossoró/RN/Brasil}

$\mathrm{O} \mathrm{CBH}$ do rio Apodi-Mossoró/RN/Brasil foi criado por Decreto Governamental № 21.881, de 10 de setembro de 2010, sendo instalado em 21 de fevereiro de 2013, com a eleição da 1a Diretoria em 22 de fevereiro de 2013, formando assim um órgão colegial com funções deliberativas (toma decisões), normativas (estabelece normas) e consultivas (emite pareceres), com composição pelos poderes públicos federal, estadual e municipal, usuários de águas e sociedade civil, com o objetivo de gerenciar as águas da bacia, compondo o Sistema Integrado de Gestão dos Recursos Hídricos - SIGERH. Ressalta-se que este processo aconteceu nos termos da Lei Estadual № 6.908, de 11 de julho de 1996, modificada pela Lei oㅜ 481 de 03 de janeiro de 2013 e em consonância com a Lei Federal ํo 9.433, de 08 de janeiro de 1997.

Nesta perspectiva, o CBH Apodi-Mossoró tem como área de atuação a totalidade da bacia hidrográfica do Rio Apodi-Mossoró, que inclui os municípios de Assu, Água Nova, Alexandria, Almino Afonso, Antônio Martins, Apodi, Areia Branca, 
Baraúna, Campo Grande, Caraúbas, Cel. João Pessoa, Dr. Severiano, Encanto, Felipe Guerra, Francisco Dantas, Frutuoso Gomes, Gov. Dix-Sept Rosado, Grossos, Itaú, Janduís, João Dias, José da Penha, Lucrécia, Luiz Gomes, Major Sales, Marcelino Vieira, Martins, Messias Targino, Mossoró, Olho d'Água do Borges, Paraná, Paraú, Patu, Pau dos Ferros, Pilões, Portalegre, Rafael Fernandes, Rafael Godeiro, Riacho da Cruz, Riacho de Santana, Rodolfo Fernandes, São Francisco do Oeste, São Miguel, Serra do Mel, Serrinha dos Pintos, Severiano Melo, Taboleiro Grande, Tenente Ananias, Umarizal, Upanema, Venha Ver e Viçosa (SEMARH, 2020).

Diante desta conceituação, o CHB Apodi-Mossoró tem por finalidades: a) promover e articular a gestão dos recursos hídricos e as ações de sua competência, considerando a bacia hidrográfica do rio Apodi-Mossoró como unidade de planejamento e gestão, apoiando a consolidação das políticas públicas afins, visando o desenvolvimento sustentável da bacia hidrográfica; b) promover o debate das questões relacionadas aos recursos hídricos e articular a atuação das entidades intervenientes e c) promover a integração nas instâncias regionais e municipais da gestão dos recursos hídricos da bacia hidrográfica.

Para isso, definiram-se como competências do CHB Apodi-Mossoró: a) aprovar e acompanhar a implementação do Plano de Recursos Hídricos da bacia hidrográfica correspondente e sugerir providências necessárias ao cumprimento de suas metas; b) aprovar a proposta de programas anuais e plurianuais e a aplicação de recursos financeiros em serviços e obras de interesse para a gestão de recursos hídricos; c) promover o debate e a cooperação entre os usuários dos recursos hídricos; d) analisar as propostas de enquadramento dos corpos hídricos e encaminhar para análise e decisão do CONERH; e) arbitrar, como primeira instância administrativa, os conflitos relacionados aos recursos hídricos; f) propor ao CONERH as acumulações, derivações, captações e lançamentos de pouca expressão para efeito de isenção da obrigatoriedade de outorga do direito de uso de água e licença de obra hidráulica; g) estabelecer os mecanismos de cobrança e sugerir os valores a serem cobrados pelo uso dos recursos hídricos; h) criar uma consciência de valorização do bem água, no âmbito da bacia hidrográfica; i) estimular, apoiar e aprovar iniciativas em educação ambiental; j) atuar junto ao CONERH; k) solicitar ao CONERH a criação da Agência de Água, no âmbito da bacia hidrográfica, ou delegação de competência a uma das entidades previstas na legislação vigente e I) aprovar o seu Regimento Interno do Comitê (SEMARH, 2020). 
No sentido de cumprir as suas competências, o $\mathrm{CBH}$ Apodi-Mossoró, para articular a sua operação, define sua composição, sendo este comitê integrado por representantes dos seguintes segmentos: usuários de água da bacia hidrográfica; sociedade civil organizada, residentes ou com atuação na bacia; e os diversos órgãos da administração federal, estadual e municipal, com atuação na bacia hidrográfica e que estejam relacionados com os recursos hídricos. Sendo assim, compõem o colegiado do Comitê 30 representantes, definidos da seguinte forma: I 12 representantes dos usuários de recursos hídricos, contabilizando ao todo $40 \%$ do colegiado; II - 09 representantes da sociedade civil organizada com atuação na bacia hidrográfica, contabilizando 30\% do colegiado; III - 09 representantes de órgãos da administração pública municipal, estadual e federal com investimentos ou competência na área da bacia, contabilizando 30\% do colegiado (SEMARH, 2020).

A partir desta composição, estrutura-se o CBH Apodi-Mossoró em Diretoria, composto por Presidente, Vice-presidente e Secretário(a) Executivo(a), eleitos pelo Plenário, para mandatos de 2 anos, podendo ser reeleitos por igual período; 0 Plenário, construído por membros dos segmentos, com duração do mandato de cada um dos representantes de 04 anos, permitida uma única recondução por igual período; e as Câmaras Técnicas, que serão formadas a partir das demandas (SEMARH, 2020).

Nesta linha de interpretação da estrutura do $\mathrm{CBH}$ Apodi-Mossoró, constataram-se as atribuições distintas conformes as funções de Presidente, Secretaria Executiva e Plenário (Quadro 02).

Quadro 02- Funções dos órgãos e dirigentes do CBH Apodi-Mossoró.

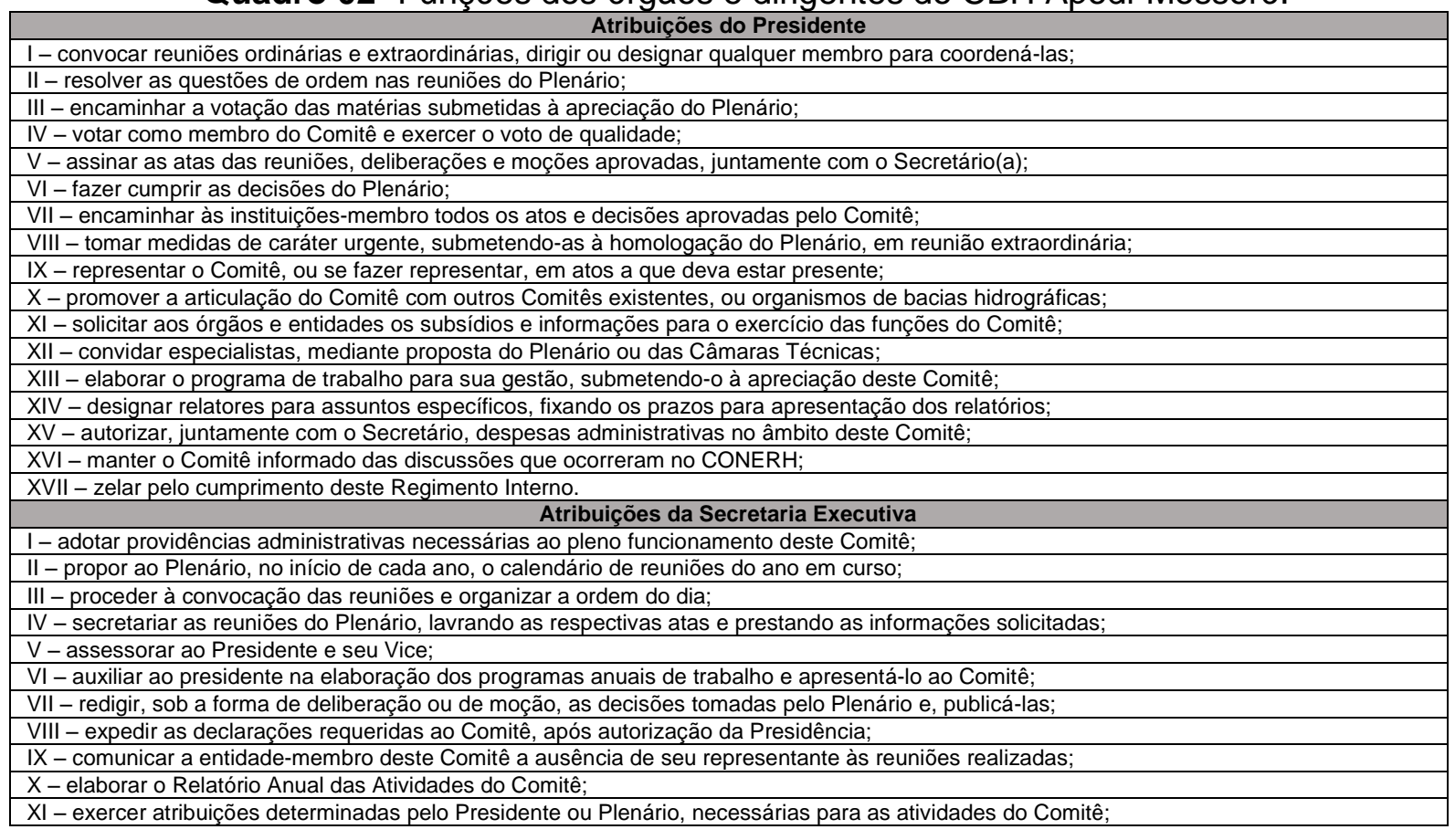


XII - organizar e divulgar a realização de audiências públicas e debates dos temas e programas definidos;

XIII - encaminhar às Câmaras Técnicas, para análise e parecer, assuntos de sua competência.

Atribuições dos Membros do CBH Apodi-Mossoró (Plenário)

I - discutir e votar as matérias que lhe forem submetidas;

II - apresentar propostas e sugerir matérias para apreciação do Plenário

III - solicitar vista de processos, devidamente justificadas, que serão apreciadas e decididas pelo Plenário:

IV - solicitar ao Presidente a convocação de reuniões extraordinárias;

$\mathrm{V}$ - propor inclusão de matéria na ordem do dia, bem como prioridade de assuntos dela constante;

VI - requerer votação nominal ou secreta, que será encaminhada de acordo com a decisão do plenário;

VII - fazer constar em ata o ponto de vista discordante do órgão ou entidade que representa;

VIII - propor o convite, de pessoas ou representantes de órgãos, para trazer subsídios às decisões do Comitê

IX - votar e ser votado para cargos previstos neste Regimento;

$\mathrm{X}$ - deliberar sobre a solicitação de vista de matérias e processos;

XI - propor a criação de Câmaras Técnicas e comissões específicas:

XII - participar das Câmaras Técnicas.

Fonte: SEMARH (2020).

Desta forma, o $\mathrm{CBH}$ Apodi-Mossoró assenta o seu funcionamento na operacionalização do plenário, que se reúnem ordinariamente 04 vezes por ano, sendo 02 reuniões por semestre e, extraordinariamente, quando convocado pelo seu presidente, ou por maioria absoluta dos membros do comitê. As referidas reuniões são instaladas com a presença de no mínimo $50 \%$ dos membros e, em segunda convocação, com um mínimo de $1 / 3$ do total de seus membros, sendo que não havendo uma segunda convocação o quórum mínimo para uma nova reunião deverá realizar-se em um prazo máximo de 10 (dez) dias e convocada por meio eletrônico, ofício circular ou FAX. Com isso, as reuniões ordinárias serão conduzidas da seguinte forma: i - abertura de sessão e verificação do quórum; ii - leitura da pauta e discussão da ordem do dia; iii - aprovação da ata da reunião anterior; iv - informes da presidência; v - deliberações da pauta; vi - Informes dos membros do Comitê e vii - encerramento. Para tanto, as deliberações e moções nas reuniões serão aprovadas por maioria simples dos membros presentes, sendo encaminhadas ao Conselho Estadual de Recursos Hídricos - CONERH, questões de sua competência, conforme previsão legal ou, ainda, aquelas que não forem resolvidas no âmbito deste Comitê.

Diante do exposto, observa-se que atualmente o $\mathrm{CBH}$ Apodi-Mossoró tem pautado as atividades para: participar do Conselho Estadual dos Recursos Hídricos; reunir representantes; elaborar minutas; debater as questões dos recursos hídricos da região; organizar eventos; participar de eventos; articular entidades; acompanhar questões técnicas; emitir relatórios; e interagir com órgãos afins da temática, dentre outras demandas referentes ao semiárido brasileiro.

\section{Atuação do CRH do Centro/Portugal e do CBH do rio Apodi-Mossoró/RN/Brasil}

Neste contexto, compararam-se os modelos de gestão dos recursos hídricos de Portugal e Brasil (Quadro 03), abordando as variáveis: caracterização dos 


\section{órgãos, atuação dos órgãos, mobilização e comunicação dos órgãos, participação}

\section{dos membros dos órgãos, atuação do representante e planejamento dos órgãos.}

Quadro 03- Comparativo da gestão dos recursos hídricos entre Portugal e Brasil.

\begin{tabular}{|c|c|c|c|}
\hline \multicolumn{2}{|c|}{ Aspecto comparativo } & Portugal ${ }^{1}$ & Brasil $^{2}$ \\
\hline \multirow{9}{*}{ 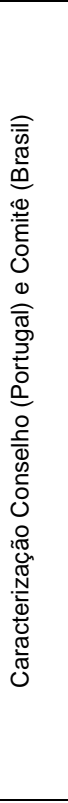 } & $\begin{array}{l}\text { Direção da } \\
\text { autarquia }\end{array}$ & $\begin{array}{l}\text { Presidido por representante do organismo público de } \\
\text { Portugal. }\end{array}$ & $\begin{array}{l}\text { Presidida por um representante da Universidade do } \\
\text { Estado do Rio Grande do Norte e outro do Sindicato } \\
\text { dos Trabalhadores e Trabalhadoras Rurais de Apodi }\end{array}$ \\
\hline & $\begin{array}{l}\text { Tempo de } \\
\text { existência }\end{array}$ & $\begin{array}{l}\text { O CRH do Centro foi instituído em } 29 \text { de maio de } \\
2007 \text {, sendo } 13 \text { anos de existência. }\end{array}$ & O CBH Apodi-Mossoró tem 6 anos de existência. \\
\hline & $\begin{array}{l}\text { Tempo de } \\
\text { representação }\end{array}$ & A atual representação do CRH do Centro tem 1 ano. & $\begin{array}{l}\text { A atual direção do CBH Apodi-Mossoró tem } 3 \text { anos } \\
\text { de representação. }\end{array}$ \\
\hline & $\begin{array}{l}\text { Quantidade de } \\
\text { membros }\end{array}$ & $\begin{array}{l}\text { O CRH do Centro é composto por até } 49 \text { membros } \\
\text { em sua totalidade. }\end{array}$ & $\begin{array}{l}\text { O CBH Apodi-Mossoró é composto por } 30 \text { membros } \\
\text { titulares e } 30 \text { membros suplentes. }\end{array}$ \\
\hline & $\begin{array}{l}\text { Descrição dos } \\
\text { segmentos }\end{array}$ & $\begin{array}{l}\text { O CRH do Centro é representado por os ministérios, } \\
\text { organismos da Administração Pública, os municípios, } \\
\text { as entidades de usos da água e, as organizações } \\
\text { técnicas, científicas e não governamentais. }\end{array}$ & $\begin{array}{l}\text { O CBH Apodi-Mossoró é distribuído pelos segmentos } \\
\text { de Poder Público, Sociedade Civil e, Usuários da } \\
\text { água. }\end{array}$ \\
\hline & $\begin{array}{l}\text { Agência de Água } \\
\text { ou Entidade }\end{array}$ & $\begin{array}{l}\text { O Conselho da ARH Centro tem relação de apreciar } \\
\text { a elaboração do Plano Nacional da Água, no } \\
\text { estabelecimento de estratégias de gestão e controlo } \\
\text { dos sistemas hídricos e acompanhar os } \\
\text { procedimentos dos planos de bacia hidrográfica. }\end{array}$ & $\begin{array}{l}\text { A Bacia Hidrográfica do rio Apodi-Mossoró não tem } \\
\text { Agência de Água. }\end{array}$ \\
\hline & $\begin{array}{c}\text { Plano de Recurso } \\
\text { Hídrico }\end{array}$ & $\begin{array}{l}\text { O Plano de Gestão do CRH do Centro tem vigência } \\
\text { para o período de } 2016-2021 \text {, revisto em } 6 \text { anos. }\end{array}$ & $\begin{array}{l}\text { A Bacia Hidrográfica do rio Apodi-Mossoró não tem } \\
\text { Plano de Recursos Hídricos. }\end{array}$ \\
\hline & $\begin{array}{l}\text { Contribuição no } \\
\text { plano }\end{array}$ & $\begin{array}{l}\text { O CRH do Centro contribuiu na elaboração do Plano } \\
\text { de Gestão da ARH, com a apreciação e } \\
\text { acompanhamento da instituição dos requisitos. }\end{array}$ & $\begin{array}{l}\text { O CBH Apodi-Mossoró ainda discutiu o Plano de } \\
\text { Recurso Hídrico em sua plenária e Câmara Técnica. }\end{array}$ \\
\hline & $\begin{array}{c}\text { Estrutura } \\
\text { administrativa }\end{array}$ & $\begin{array}{l}\text { Formada por: Diretoria, Divisão de Recursos Hídricos } \\
\text { Interiores, Divisão de Recursos Hídricos do Litoral, } \\
\text { Divisão de Planeamento e Informação, Divisão de } \\
\text { Assuntos Administrativos e Financeiros e, Divisão da } \\
\text { Ria de Aveiro e Gestão de Infraestruturas. }\end{array}$ & $\begin{array}{l}\text { O CBH Apodi-Mossoró tem uma diretoria formada } \\
\text { pelo presidente, vice-presidente e secretário e, } \\
\text { câmara técnica para apoio a gestão e assuntos } \\
\text { especiais. }\end{array}$ \\
\hline \multirow{10}{*}{ 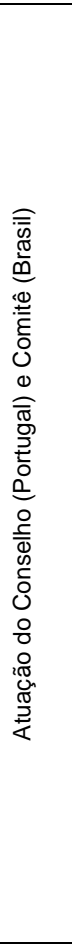 } & $\begin{array}{l}\text { Atuação da } \\
\text { autarquia }\end{array}$ & $\begin{array}{l}\text { O CRH do Centro atua com: elaboração do plano de } \\
\text { gestão; proposta de qualidade da água; parecer } \\
\text { sobre a taxa; repartição das águas; medidas contra a } \\
\text { poluição; propostas para as bacias; avaliando o } \\
\text { plano de atividades e o relatório e contas da ARH e; } \\
\text { acompanhando o plano de investimentos. }\end{array}$ & $\begin{array}{l}\text { O CBH Apodi-Mossoró atua com: reuniões, visitas } \\
\text { técnicas, elaboração de minuta, emissão de } \\
\text { relatórios, debates ambientais, participação e } \\
\text { organização de eventos, consultivo, deliberativo e, } \\
\text { normativo. }\end{array}$ \\
\hline & $\begin{array}{l}\text { Periodicidade das } \\
\text { reuniões }\end{array}$ & $\mathrm{O} \mathrm{CRH}$ do Centro tem 3 reuniões ao longo do ano. & O CBH Apodi-Mossoró se reúne de forma trimestral. \\
\hline & $\begin{array}{l}\text { Temáticas das } \\
\text { reuniões }\end{array}$ & $\begin{array}{l}\text { Os debates nas reuniões referem-se: quadro } \\
\text { institucional, quantidade e qualidade de água, gestão } \\
\text { de risco e, monitoramento ambiental. }\end{array}$ & $\begin{array}{l}\text { Os principais debates ocorridos nas reuniões do } \\
\text { CBH Apodi-Mossoró referem-se a gestão de } \\
\text { conflitos, monitoramento ambiental e participação } \\
\text { popular. }\end{array}$ \\
\hline & $\begin{array}{l}\text { Atuação dos } \\
\text { representantes }\end{array}$ & $\begin{array}{l}\text { A atuação dos representantes do } \mathrm{CRH} \text { do Centro } \\
\text { ocorre de forma distinta, devido as diretrizes legais } \\
\text { limitarem a participação, sendo o poder público muito } \\
\text { participativo, enquanto a sociedade civil e iniciativa } \\
\text { privada participativos, com restrições. }\end{array}$ & $\begin{array}{l}\text { A atuação dos representantes do CBH Apodi- } \\
\text { Mossoró ocorre de forma distinta, sendo a sociedade } \\
\text { civil e o poder público muito participativo, enquanto a } \\
\text { iniciativa privada participativa e, atores externos sem } \\
\text { participação. }\end{array}$ \\
\hline & $\begin{array}{l}\text { Conflitos nas } \\
\text { reuniões }\end{array}$ & $\begin{array}{l}\text { Os principais conflitos nas reuniões do } \mathrm{CRH} \text { do } \\
\text { Centro referem-se aos pontos de pauta e dinâmica } \\
\text { das reuniões. }\end{array}$ & $\begin{array}{l}\text { Os principais conflitos nas reuniões do } \mathrm{CBH} \text { Apodi- } \\
\text { Mossoró referem-se aos pontos de pauta. }\end{array}$ \\
\hline & $\begin{array}{l}\text { Resoluções dos } \\
\text { conflitos }\end{array}$ & $\begin{array}{l}\text { Os principais conflitos nas reuniões do } \mathrm{CRH} \text { do } \\
\text { Centro são resolvidos em planária, mas com votação } \\
\text { limitadas para alguns membros. }\end{array}$ & $\begin{array}{l}\text { Os principais conflitos nas reuniões do CBH Apodi- } \\
\text { Mossoró são resolvidos dialogados na plenária. }\end{array}$ \\
\hline & $\begin{array}{l}\text { Carências nas } \\
\text { reuniões }\end{array}$ & $\begin{array}{l}\text { Nas reuniões do } \mathrm{CRH} \text { do Centro existem carências } \\
\text { relacionadas com mais diálogos. }\end{array}$ & $\begin{array}{l}\text { Nas reuniões do CBH Apodi-Mossoró não existem } \\
\text { carências. }\end{array}$ \\
\hline & $\begin{array}{l}\text { Dificuldades de } \\
\text { funcionamento }\end{array}$ & $\begin{array}{l}\text { O CRH do Centro tem dificuldades de funcionamento } \\
\text { relacionadas com disponibilidade de tempo e } \\
\text { articulação entre os membros. }\end{array}$ & $\begin{array}{l}\mathrm{O} \mathrm{CBH} \text { Apodi-Mossoró tem dificuldades de } \\
\text { funcionamento relacionadas com estrutura e custeio. }\end{array}$ \\
\hline & $\begin{array}{l}\text { Interação com a } \\
\text { sociedade }\end{array}$ & $\begin{array}{l}\text { A interação O CRH do Centro com a sociedade } \\
\text { ocorre de forma limitada, visto que os membros } \\
\text { deste segmento tem atuação limitada nas reuniões. }\end{array}$ & $\begin{array}{l}\text { A interação do CBH Apodi-Mossoró com a sociedade } \\
\text { ocorre de forma espontânea. }\end{array}$ \\
\hline & $\begin{array}{l}\text { Articulação com } \\
\text { instituições }\end{array}$ & $\mathrm{O} \mathrm{CRH}$ do Centro articula-se com outros organismos. & $\begin{array}{l}\text { O CBH Apodi-Mossoró articula-se com outras } \\
\text { instituições, oficiando e participando de reuniões. }\end{array}$ \\
\hline \multirow{9}{*}{ 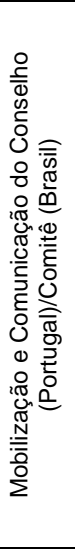 } & $\begin{array}{l}\text { Comunicação } \\
\text { entre membros }\end{array}$ & $\begin{array}{l}\text { A comunicação entre membros do } \mathrm{CRH} \text { do Centro } \\
\text { ocorre através de e-mail. }\end{array}$ & $\begin{array}{l}\begin{array}{l}\text { Ocorre através de e-mail e } \\
\text { mensagens. }\end{array} \\
\end{array}$ \\
\hline & $\begin{array}{c}\text { Meios de } \\
\text { informação }\end{array}$ & $\begin{array}{l}\text { Principais meios de informação: homepage (do } \\
\text { organismo nacional de recursos hídricos) e e-mail. }\end{array}$ & $\begin{array}{l}\text { O CBH Apodi-Mossoró tem como principais meios de } \\
\text { informação: homepage, redes sociais e e-mail. }\end{array}$ \\
\hline & $\begin{array}{l}\text { Responsável pela } \\
\text { informação }\end{array}$ & $\begin{array}{l}\text { O responsável pela informação do } \mathrm{CRH} \text { do Centro é } \\
\text { a diretoria. }\end{array}$ & $\begin{array}{l}\text { O responsável pela informação do } \mathrm{CBH} \text { Apodi- } \\
\text { Mossoró é a diretoria e a secretaria executiva. }\end{array}$ \\
\hline & $\begin{array}{c}\text { Responsável pela } \\
\text { organização }\end{array}$ & $\begin{array}{l}\text { O responsável do CRH do Centro é a Diretoria e } \\
\text { Divisão de Planeamento e Informação - DPI }\end{array}$ & $\begin{array}{l}\text { O responsável pela organização do } \mathrm{CBH} \text { Apodi- } \\
\text { Mossoró é a Diretoria a Secretaria Executiva. }\end{array}$ \\
\hline & $\begin{array}{l}\text { Planejamento da } \\
\text { divulgação }\end{array}$ & $\begin{array}{l}\text { O planejamento da divulgação do CRH do Centro } \\
\text { ocorre com reunião da Diretoria, DPI e, Divisão de } \\
\text { Assuntos Administrativos e Financeiros - DAF. }\end{array}$ & $\begin{array}{l}\text { O planejamento da divulgação do } \mathrm{CBH} \text { Apodi- } \\
\text { Mossoró ocorre com reunião da diretoria. }\end{array}$ \\
\hline & $\begin{array}{l}\text { Formas de } \\
\text { divulgação }\end{array}$ & $\begin{array}{l}\text { As formas de divulgação do } \mathrm{CRH} \text { do Centro para } \\
\text { sociedade é com e-mail e homepage (do organismo } \\
\text { nacional de recursos hídricos). }\end{array}$ & $\begin{array}{l}\text { As formas de divulgação do CBH Apodi-Mossoró } \\
\text { para sociedade é com e-mail e redes sociais. }\end{array}$ \\
\hline & $\begin{array}{l}\text { Interação com } \\
\text { órgãos oficiais }\end{array}$ & $\begin{array}{l}\text { A interação do } \mathrm{CRH} \text { do Centro com órgãos oficiais } \\
\text { ocorre com e-mail, comunicados e telefone. }\end{array}$ & $\begin{array}{l}\text { A interação do CBH Apodi-Mossoró com órgãos } \\
\text { oficiais ocorre com e-mail, comunicados e telefone. }\end{array}$ \\
\hline & $\begin{array}{l}\text { Definição das } \\
\text { reuniões }\end{array}$ & $\begin{array}{l}\text { A definição dos temas das reuniões do } \mathrm{CRH} \text { do } \\
\text { Centro se dá por e-mail, comunicados e telefone. }\end{array}$ & Se dá por grupo de aplicativos de mensagens. \\
\hline & Dificuldades na & As principais dificuldade da mobilização do $\mathrm{CRH}$ do & As principais dificuldade da mobilização do $\mathrm{CBH}$ \\
\hline
\end{tabular}




\begin{tabular}{|c|c|c|c|}
\hline & mobilização & Centro referem-se a falta de estrutura. & Apodi-Mossoró referem-se a falta de estrutura. \\
\hline & $\begin{array}{l}\text { Dificuldades na } \\
\text { comunicação }\end{array}$ & $\begin{array}{l}\text { As dificuldade referem-se a falta de tempo e } \\
\text { interação entre os membros. }\end{array}$ & $\begin{array}{l}\text { As principais dificuldade da comunicação do } \mathrm{CBH} \\
\text { Apodi-Mossoró referem-se a falta de pessoal. }\end{array}$ \\
\hline \multirow{10}{*}{ 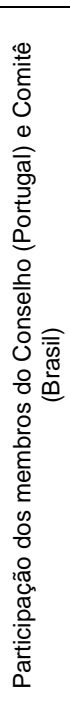 } & $\begin{array}{l}\text { Participação dos } \\
\text { membros }\end{array}$ & $\begin{array}{l}\text { A participação dos membros do } \mathrm{CRH} \text { do Centro } \\
\text { ocorre de forma razoável. }\end{array}$ & $\begin{array}{l}\text { A participação dos membros do CBH Apodi-Mossoró } \\
\text { ocorre de forma frequente. }\end{array}$ \\
\hline & $\begin{array}{l}\text { Interesse dos } \\
\text { membros }\end{array}$ & $\begin{array}{l}\text { O interesse dos membros do } \mathrm{CRH} \text { do Centro é } \\
\text { percebível de forma mediana. }\end{array}$ & $\begin{array}{l}\text { O interesse dos membros do CBH Apodi-Mossoró é } \\
\text { percebível de forma alta. }\end{array}$ \\
\hline & $\begin{array}{l}\text { Diversidade dos } \\
\text { segmentos }\end{array}$ & $\begin{array}{l}\text { A diversidade dos membros do } \mathrm{CRH} \text { do Centro } \\
\text { ocorre de forma alta. }\end{array}$ & $\begin{array}{l}\text { A diversidade dos membros do CBH Apodi-Mossoró } \\
\text { ocorre de forma alta. }\end{array}$ \\
\hline & $\begin{array}{l}\text { Quantidade dos } \\
\text { membros }\end{array}$ & $\begin{array}{l}\text { A quantidade dos membros do } \mathrm{CRH} \text { do Centro } \\
\text { ocorre de forma prioritária para alguns segmentos, } \\
\text { como organismos oficiais. }\end{array}$ & $\begin{array}{l}\text { A quantidade dos membros do CBH Apodi-Mossoró } \\
\text { ocorre de forma paritária. }\end{array}$ \\
\hline & $\begin{array}{l}\text { Forma de escolha } \\
\text { dos membros }\end{array}$ & $\begin{array}{l}\text { A forma de escolha dos membros do } \mathrm{CRH} \text { do Centro } \\
\text { ocorre a partir de indicação dos representantes. }\end{array}$ & $\begin{array}{l}\text { Ocorre por eleição, sendo necessário demostrar } \\
\text { interesse em participar. }\end{array}$ \\
\hline & $\begin{array}{c}\text { Nível de } \\
\text { conhecimento }\end{array}$ & $\begin{array}{l}\text { O nível de conhecimento dos membros do } \mathrm{CRH} \text { do } \\
\text { Centro é heterogêneo, sendo muito alto do poder } \\
\text { público e regular para demais segmentos. }\end{array}$ & $\begin{array}{l}\text { O nível de conhecimento dos membros do } \mathrm{CBH} \\
\text { Apodi-Mossoró é heterogêneo, sendo muito alto do } \\
\text { poder público e regular para demais segmentos. }\end{array}$ \\
\hline & $\begin{array}{l}\text { Interação entre } \\
\text { os membros }\end{array}$ & $\begin{array}{l}\text { A interação entre os membros do CRH do Centro } \\
\text { ocorre de forma baixa devido limitação na atuação. }\end{array}$ & $\begin{array}{l}\text { A interação entre os membros do } \mathrm{CBH} \text { Apodi- } \\
\text { Mossoró ocorre de forma razoável. }\end{array}$ \\
\hline & $\begin{array}{l}\text { Participação da } \\
\text { sociedade civil }\end{array}$ & $\begin{array}{l}\text { A participação da sociedade civil no } \mathrm{CRH} \text { do Centro } \\
\text { ocorre de forma fragilizada devido baixo poder de } \\
\text { decisão. }\end{array}$ & $\begin{array}{l}\text { A participação da sociedade civil do CBH Apodi- } \\
\text { Mossoró ocorre de forma fragilizada devido baixa } \\
\text { capacitação. }\end{array}$ \\
\hline & $\begin{array}{l}\text { Participação do } \\
\text { poder público }\end{array}$ & $\begin{array}{l}\text { A participação do poder público no } \mathrm{CRH} \text { do Centro } \\
\text { ocorre de forma alta devido maior representatividade. }\end{array}$ & $\begin{array}{l}\text { A participação do poder público do CBH Apodi- } \\
\text { Mossoró ocorre de forma satisfatório devido apoio } \\
\text { estrutural e financeiro. }\end{array}$ \\
\hline & $\begin{array}{l}\text { Partici } \\
\text { setor }\end{array}$ & $\begin{array}{l}\text { A participação do setor privado no } \mathrm{CRH} \text { do Centro } \\
\text { ocorre de forma razoável devido restrições no } \\
\text { quantitativos de representantes. }\end{array}$ & $\begin{array}{l}\text { A participação do setor privado do } \mathrm{CBH} \text { Apodi- } \\
\text { Mossoró ocorre de forma limitada, com necessidade } \\
\text { de maior interação dos grandes usuários. }\end{array}$ \\
\hline & $\begin{array}{r}\text { Motive } \\
\text { pres }\end{array}$ & $\begin{array}{l}\text { O presidente do } \mathrm{CRH} \text { do Centro tem motivação } \\
\text { técnica e cívica. }\end{array}$ & $\begin{array}{l}\text { O presidente do CBH Apodi-Mossoró tem motivação } \\
\text { científica e cívica. }\end{array}$ \\
\hline$\underset{\frac{\Phi}{\sigma}}{\Phi}$ & $\begin{array}{l}\text { Contribuição do } \\
\text { presidente }\end{array}$ & $\begin{array}{l}\text { A contribuição da presidência do } \mathrm{CRH} \text { do Centro é } \\
\text { avaliada como alta, pela inserção técnica dos } \\
\text { organismos ambiental de Portugal. }\end{array}$ & $\begin{array}{l}\text { A contribuição da presidência do } \mathrm{CBH} \text { Apodi- } \\
\text { Mossoró é avaliada como alta, pela inserção política } \\
\text { da universidade e acesso ao conhecimento técnico. }\end{array}$ \\
\hline $\begin{array}{l}\frac{0}{0} \\
\frac{0}{2} \\
\frac{1}{2} \\
0\end{array}$ & $\begin{array}{l}\text { Dificuldades do } \\
\text { presidente }\end{array}$ & $\begin{array}{l}\text { As maiores dificuldades da diretoria do } \mathrm{CRH} \text { do } \\
\text { Centro referem-se articular interesses dos } \\
\text { segmentos. }\end{array}$ & $\begin{array}{l}\text { As maiores dificuldades da presidência do } \mathrm{CBH} \\
\text { Apodi-Mossoró referem-se recursos financeiros, } \\
\text { tempo e, compatibilizar com outras ocupações. }\end{array}$ \\
\hline 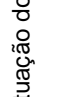 & $\begin{array}{l}\text { Interação do } \\
\text { presidente }\end{array}$ & $\begin{array}{l}\text { A diretoria do } \mathrm{CRH} \text { do Centro consegue interagir de } \\
\text { forma alta com todos os membros, sendo } \\
\text { heterogênea. }\end{array}$ & $\begin{array}{l}\text { A presidência do CBH Apodi-Mossoró consegue } \\
\text { interagir de forma elevada com todos os membros. }\end{array}$ \\
\hline 严 & $\begin{array}{l}\text { Melhorias para } \\
\text { presidência }\end{array}$ & $\begin{array}{l}\text { As melhorias na diretoria do CRH do Centro se dará } \\
\text { com investimento técnico e financeiro, em especial } \\
\text { para recursos humanos, equipamentos e, } \\
\text { comunicação. }\end{array}$ & $\begin{array}{l}\text { As melhorias na presidência do CBH Apodi-Mossoró } \\
\text { se dará com investimento em sede própria, recursos } \\
\text { humanos permanentes, veículo próprio e, a } \\
\text { implementação dos instrumentos do plano. }\end{array}$ \\
\hline & $\begin{array}{r}\text { Planeje } \\
\text { ativ }\end{array}$ & $\begin{array}{l}\text { O planejamento de atividades do } \mathrm{CRH} \text { do Centro } \\
\text { ocorre anualmente pela diretoria. }\end{array}$ & $\begin{array}{l}\text { O planejamento de atividades do } \mathrm{CBH} \text { Apodi- } \\
\text { Mossoró ocorre de forma razoável, sendo anual. }\end{array}$ \\
\hline & $\begin{array}{l}\text { Planejamento } \\
\text { com outro setor }\end{array}$ & $\begin{array}{l}\text { O planejamento de atividades do CRH do Centro tem } \\
\text { alta interação com organismos públicos e, moderado } \\
\text { com outros segmentos. }\end{array}$ & $\begin{array}{l}\text { O planejamento de atividades do } \mathrm{CBH} \text { Apodi- } \\
\text { Mossoró tem alta interação com outros setores, em } \\
\text { especial com o poder público. }\end{array}$ \\
\hline 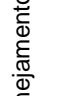 & $\begin{array}{l}\text { Prioridades da } \\
\text { autarquia }\end{array}$ & $\begin{array}{l}\text { As prioridades do CRH do Centro referem-se ao } \\
\text { monitoramento, fiscalização e comunicação. }\end{array}$ & $\begin{array}{l}\text { As prioridades do CBH Apodi-Mossoró referem-se à } \\
\text { implementação dos instrumento do plano e, em } \\
\text { especial o pagamento pelo uso da água bruta. }\end{array}$ \\
\hline$\frac{\frac{\tilde{\sigma}}{\alpha}}{\alpha}$ & $\begin{array}{c}\text { Plano de ação } \\
\text { para prioridades }\end{array}$ & $\begin{array}{l}\text { O plano de ação das prioridades do CRH do Centro } \\
\text { visa revisão do Plano de Gestão da Região } \\
\text { Hidrográfica. }\end{array}$ & $\begin{array}{l}\text { O plano de ação das prioridades do CBH Apodi- } \\
\text { Mossoró visa maior interação com o poder público } \\
\text { para maiores agendas de debates. }\end{array}$ \\
\hline & Desafios futuros & $\begin{array}{l}\text { O maiores desafios do CRH do Centro referem-se a } \\
\text { maior interação com todos os segmentos, para ter } \\
\text { mais participação }\end{array}$ & $\begin{array}{l}\text { O maiores desafios do CBH Apodi-Mossoró referem- } \\
\text { se a busca por mais autonomia, para ter uma } \\
\text { atuação isenta. }\end{array}$ \\
\hline
\end{tabular}

${ }^{1}$ Este conteúdo baseou-se na entrevista do Presidente do $\mathrm{CRH}$ do Centro/Portugal.

2 Este conteúdo baseou-se na entrevista do Presidente do $\mathrm{CBH}$ do rio Apodi-Mossoró/RN/Brasil.

Diante do evidenciado no Quadro 03, constataram-se diferenças similaridades entre as formas de GRH de Portugal e do Brasil. Sendo assim, em termos de caracterização do $\mathrm{CRH}$ do Centro e do $\mathrm{CBH}$ do rio Apodi-Mossoró, observa-se que no caso português trata-se de uma instituição com maior tempo, quantidade, diversidade e estrutura de representação, consequentemente resulta em uma contribuição mais consolidada na elaboração de instrumentos de gestão dos recursos hídricos e interação com outros organismos relacionados com a temática.

Os resultados obtidos dialogam com os de Agra Filho e Ramos (2015) ao afirmarem que a DQA exerce influência como principais referenciais indutores da sustentabilidade, face à relevância de se adotarem prévias definições de diretrizes e 
enquadramentos estratégicos como norteadores da elaboração dos planos de bacias hidrográficas, permitindo assim aplicação da Avaliação Ambiental Estratégica - AAE como um instrumento inovador fundamental para se consolidar a perspectiva da sustentabilidade. Isto posto, observa-se ainda a necessidade de avanços na GRH em Portugal e no Brasil, em que Ferreira e Debeus (2018) abordam problemas em questões de monitoramento e comunicação que, sendo questões que necessitam mudanças na maneira como a política e sociedade se relacionam, além de recursos.

A partir da estruturação destes modelos de $\mathrm{GRH}$, são delineadas as formas de atuação, através, em ambos os casos, dos poderes consultivo, deliberativo e normativo, porém, no caso português observou-se mais efetividade nas ações, o que possivelmente será explicado pelo tempo de existência, maior interação com o poder público e adoção de instrumentos de gestão. Entretanto, é possível relatar que a atuação na gestão brasileira ocorre de forma mais participativa, ou seja, através de maior incidência nas plenárias. Ainda é possível destacar a heterogeneidade quanto à operacionalidade das ações, visto que se tem maior adesão em Portugal e, com um debate para questões técnicas, enquanto no Brasil é uma discussão mais política.

Sendo assim, estes dados refletem as diferenças no atual cenário da GRH de Portugal e do Brasil, já que diversos autores em seus estudos determinaram uma carência de poder decisório nos novos arranjos institucionais que impede que 0 processo se efetive, apesar de todos os benefícios assinalados com a participação pública no Brasil (Campos e Francalanza, 2010), ambos os países tem deficiências na exploração das oportunidades oferecidas pelos dispositivos legais sobre recursos hídricos (Alovisi Júnior e Berezuk, 2012), no Brasil a participação pública é mais efetiva, visto que tem caráter deliberativo garantido aos comitês de bacia pela Lei $\mathrm{n}^{\circ}$ 9.433/97 (Amorim et al., 2015) e que na Lei brasileira a água é um recurso público que deve ser gerido pelo Estado e usada pela população com prioridade, enquanto em Portugal a água, um bem público, porém difere ao não colocar o consumo humano como prioridade, dando enfoque na qualidade ecológica da água, através de classes e tipologias de corpos d'água para conservar e proteger os ecossistemas aquáticos, melhorando a qualidade hídrica no geral (Casarin, 2017). Dessa forma, este cenário corrobora a tese da necessidade de maior divulgação das ações destes dispositivos.

Com isso, a efetivação da GRH em Portugal e no Brasil se dará com sistemas de mobilização e comunicação aperfeiçoados, sendo constatado que o $\mathrm{CRH}$ do 
Centro apresenta mecanismos mais formais e centralizados com a Direção, enquanto o $\mathrm{CBH}$ do rio Apodi-Mossoró/RN adota formas mais diversificadas e informais, sendo compartilhada a responsabilidade com a Secretaria Executiva e demais membros.

Este cenário de fragilidades no modelo de $\mathrm{GRH}$ no Brasil foi ratificado por Fadul, Vitoria e Cerqueira (2017), relacionado com o plano operacional de funcionamento dos comitês como no plano social e político, no exercício real do processo participativo. Campos e Francalanza (2010), afirmaram a necessidade de desenvolver as relações entre os atores envolvidos a fim de ampliar a confiança e a cooperação entre os mesmos na gestão de um recurso comum como a água, alcançando benefícios a toda a coletividade. Por seu turno, Cerqueira et al. (2016) constataram maior necessidade de participação popular e institucional nos comitês. Finalmente, Luz (2017) revelou a necessidade de haver comprometimento na execução de responsabilidades do Estado, Gestores, Membros e Cidadãos para que o gerenciamento da bacia hidrográfica Taquari-Antas seja desempenhado com plenitude nas atribuições. Em Portugal, Ribeiro (2016) evidenciou que existem características de centralização, que os CRH's serviram, como espaços de prestação de informações da administração para os outros segmentos representados, dificultando assim a eficiência na comunicação e a democratização da gestão.

Neste contexto de articulação, a participação dos membros na GRH no Brasil e em Portugal, ocorre de forma discrepante, sendo no $\mathrm{CRH}$ do Centro menos participativa em comparado com o $\mathrm{CBH}$ do rio Apodi-Mossoró/RN, devido à limitação de atuação e ao baixo poder de atuação, em especial para sociedade civil.

Este pensamento é explicado por Vasconcelos et al. (2011), que verificaram que mesmo com a DQA, que encoraja os Estados Membros a conduzir processos de participação ativos, e mesmo de governança para uma gestão participada dos recursos hídricos, em Portugal o sucesso da participação tem sido limitado, devido a utilização de formatos passivos de participação nos processos de consulta e de disponibilização de informação. Ribeiro, Ribeiro e Varanda (2016) identificaram que em Portugal, embora o setor governamental local tenha demonstrado uma percentagem mais elevada de participação, principalmente relacionada com a Taxa de Recursos Hídricos - TRH, os setores da sociedade civil, devido à baixa capacidade e experiência de organização nas reuniões, tiveram poucas e pouco eficazes contribuições. Ribeiro (2016) determinou que em Portugal, nos momentos 
em que o conselho exerceu a sua função consultiva e no caso do Brasil, a função deliberativa contribuiu de forma significativa com as modificações na gestão das águas, ainda que apresentando falhas em ambos os países, no caso brasileiro no que se refere à motivação dos membros, enquanto na situação portuguesa no que diz respeito à maior diversidade dos atores. Desta forma, a participação dos agentes não deve ser utilizada apenas para a representação de segmentos interessados conforme previsto na lei - pois o princípio democrático de representação deve estar associado à legitimidade e à representatividade, assegurando que os diferentes segmentos possam atuar com autonomia e coerência (RIBEIRO; RIBEIRO E VARANDA, 2016).

Nesta perspectiva de compreender o funcionamento dos modelos de GRH de Portugal e Brasil apurou-se a atuação dos seus representantes maiores, sendo no $\mathrm{CRH}$ do Centro relacionada com motivação técnica, enquanto no $\mathrm{CBH}$ do rio ApodiMossoró/RN se deve pela motivação científica. Neste ensejo, verificaram-se também dificuldades diferentes, no caso português relacionadas com a articulação dos interesses dos segmentos, enquanto no âmbito brasileiro devidas aos recursos financeiros e ao tempo necessário. Apesar deste quadro de diferenças, ainda é possível notar que em ambas as situações necessitam de maiores investimentos para o seu funcionamento, em especial nos recursos humanos.

Nesta mesma linha de pensamento, diversos autores destacam as diferenças entre os modelos de Portugal e Brasil. Silva et al. (2018), referem que, no caso brasileiro, a temática da qualidade da água ainda é recente, visto que a legislação não demonstra preocupação com os bioindicadores, enquanto em Portugal, com a DQA, já se realiza essa mensuração, tornando-se mais abrangente, já que a avaliação realizada tem como objetivo alcançar um bom estado ecológico. Por outro lado, Travassos (2013) determinou que no Brasil se tem uma grande evolução na experiência do gerenciamento, principalmente relacionada com a descentralização das competências, enquanto Portugal tem experiência com abordagem ecológica, favorecendo a definição de estratégias e implementações de programas que visem a conservação e/ou recuperação dos ambientes hídricos. Desta forma, notou-se que o ajuste de algumas etapas da DQA seria uma alternativa promissora na gestão dos $\mathrm{RH}$ no Brasil, em especial nas etapas iniciais da implementação da DQA com enfoque nos avanços científicos obtidos (SILVA; FERREIRA e POMPÊO, 2013).

Para efetivar os instrumentos de $\mathrm{GRH}$, faz-se necessário aperfeiçoar as formas de planejamento, sendo que em Portugal ocorre com maior interação com 
outros órgãos ambientais, apresentando prioridades para monitoramento, fiscalização, comunicação e revisão do Plano de Gestão, enquanto no Brasil as prioridades referem-se à busca de mais participação para elaboração do plano da bacia. Isto posto, percebe-se que apesar de apresentarem prioridades diferentes, visto que estão em momentos de gestão distintos, ambos os organismos buscam como desafios futuros mais autonomia na participação dos debates da gestão dos recursos hídricos.

Este cenário de evolução das políticas de GRH é corroborado por Costa et al. (2011) ao identificarem que a preocupação com as águas em Portugal não é recente, sendo sua legislação para a GRH anterior às leis brasileiras. Magalhães et al. (2011) referem que os resultados obtidos com os modelos de gestão proporcionaram ganhos a nível ambiental, na regulação dos usos e na conservação dos recursos, e a nível social, propiciados pela maior participação popular e validação dos direitos dos cidadãos principalmente pela água ser reconhecida como um bem de domínio público. Este fato é exaltado por Silva, Herrero e Borges (2017) os quais constataram que os instrumentos da política permitem o uso racional da água e, finalmente, é criticado por Martins (2015) que afirmou que se torna necessária uma aproximação paulatina da efetiva noção de parlamento das águas, focando os usos e os saberes múltiplos.

Nesta perspectiva, faz-se necessário estimular planos futuros para aperfeiçoamento dos modelos de gestão dos recursos hídricos, sendo delineados estudos científicos por Schimdt e Ferreira (2013), Feil, Strasburg e Spilki (2017) e Lopes e Neves (2017), que orientam a necessidade de incentivar uma participação popular mais efetiva, por Amorim, Ribeiro e Braga (2016), Barros, Paiva e Cisneiros (2017), Costa (2017) e Trindade, Scheibe e Ribeiro (2018) que direcionaram suas contribuições para evolução do arranjo institucional, por Vasconcelos et al. (2016) e Young e Sedoura (2019) que ressaltam que as tendências no planejamento da GRH deve ter uma abordagem integrada, considerando inclusivamente o ordenamento do solo como ferramenta importante para manter e restaurar os cursos de água, e, finalmente, por Bolson e Haonat (2016) e Caldas et al. (2019), que apontaram a necessidade de se mesclar democraticamente os princípios da dignidade humana e dos bens comuns com os interesses locais, nacionais e internacionais, sob a forma de Parcerias Público-Privadas - PPPs.

Diante do apresentado, faz-se necessário sistematizar os modelos de GRH do $\mathrm{CRH}$ do Centro e do $\mathrm{CBH}$ do rio Apodi-Mossoró/RN em aspectos negativos e 
positivos, para aperfeiçoá-los com características potenciais e desafiadores.

\section{Considerações finais}

As transformações da sociedade e da natureza nos últimos anos, proporcionaram um cenário de crise ambiental, produzindo debates internacionais, em especial para os recursos hídricos, por serem considerados estratégicos no desenvolvimento humano e da vida na terra, tornando-se crucial a necessidade de políticas públicas para estes sistemas ambientais.

Com isso, os Estados Nações instituíram suas políticas ambientais voltadas para a conciliação dos interesses ambientais, sociais e econômicos, sendo estas depois setorizadas a partir dos respectivos tipos de recursos naturais. No caso específico dos recursos hídricos, foram instituídos dispositivos de participação e de governança para aperfeiçoar o uso racional dos recursos hídricos em cada país.

Em Portugal, no seu arcabouço jurídico, a água é considerada como um recurso ecológico, que permite ser um bem público sem prioridade para uso da população, sendo gerido com participação pública através dos CRH's que são essencialmente informativos e consultivos. No Brasil, os recursos hídricos são definidos em seus atos legais como naturais e econômicos, permitindo que sejam recursos públicos geridos pelo Estado com uso prioritário para população, o que possibilita a constituição dos CBH's com caráter de negociadores e deliberativos.

Os modelos de $\mathrm{GRH}$ de Portugal e do Brasil, especificamente o $\mathrm{CRH}$ do Centro e o $\mathrm{CBH}$ do rio Apodi-Mossoró, apresentam comportamentos distintos em suas atuações, já que no caso português trata-se de um conselho com maior tempo de atuação, quantidade, diversidade e estrutura de representação, permitindo uma contribuição na elaboração de instrumentos de $\mathrm{GRH}$, enquanto na situação brasileira ocorre de forma menos técnica, mas, mais participativa, e democrática.

Diante deste cenário de efetivação GRH nos casos analisados, recomenda-se para o $\mathrm{CRH}$ do Centro que dê prioridade ao monitoramento, fiscalização, comunicação e revisão do Plano de Gestão, enquanto para o $\mathrm{CBH}$ do rio ApodiMossoró se deve enfatizar a elaboração do plano da bacia.

Neste contexto, ainda que reducionista, orienta-se o aperfeiçoamento destes modelos de $\mathrm{GRH}$, sendo orientados nas diretrizes da revisão dos fundamentos gerais e objetivos, recapitulação da política de recursos hídricos e instrumentos de gestão, reconsideração do gerenciamento dos recursos hídricos, reavaliação dos programas de medidas e atualização dos planos futuros. 
Para tanto, é salutar destacar que ao longo deste ensaio científico, foram identificadas limitações voltadas para o quadro conceitual, ao equiparar os instrumentos de GRH de Portugal e do Brasil; operacional, ao articular a execução da pesquisa de campo, sendo possível através do envio do instrumento de pesquisa previamente, fazendo depois a conferência dos dados; e didática, ao organizar os dados qualitativos obtidos, procedendo-se por síntese e análise de discurso por categorias teóricas. Desta forma, recomenda-se a continuação de estudos voltados para avaliação da participação social na gestão da água.

\section{REFERÊNCIAS}

AGRA FILHO, S. S.; RAMOS, T. B. Análise do modelo institucional de gestão da água para a aplicação da AAE: estudo comparativo entre Portugal e Brasil. Revista Eletrônica de Gestão e Tecnologias Ambientais (GESTA), Bahia, v. 3, n. 2, 2015.

ALBUFEIRA. Convenção sobre Cooperação para a Protecção e o Aproveitamento Sustentável das Águas das Bacias Hidrográficas Luso-espanholas, 1998.

ALOVISI JÚNIOR, V.; BEREZUK, A. G. Análise comparativa de gestão de recursos hídricos em Portugal e no Brasil. Associação Portuguesa dos Recursos Hídricos, Lisboa, v. 33, n. $1,2012$.

AMORIM, A. L.; RIBEIRO; M. M. R.; BRAGA, C. F. C. Conflitos em bacias hidrográficas compartilhadas: o caso da bacia do rio Piranhas-Açu/PB-RN. Revista Brasileira de Recursos Hídricos, Porto Alegre, v. 21, n.1, 2016.

AMORIM, A. L. et al. Marcos Regulatórios e Convenção de Albufeira: a participação pública nos mecanismos de gestão e planejamento da água no Brasil e na Península Ibérica. In: XXI SIMPÓSIO BRASILEIRO DE RECURSOS HÍDRICOS, 2015, Brasília. Anais [...]. Brasília: $\mathrm{ABRH}, 2015$.

ANA. Agência Nacional das Águas - ANA. Gestão das Águas 2019. Brasília: 2019. Disponível em: https://www.ana.gov.br/gestao-da-agua/sistema-de-gerenciamento-derecursos-hidricos. Acesso em: 10 fev. 2020.

APA. Agência Portuguesa do Ambiente - APA. Água 2019. Disponível em: https://apambiente.pt/. Acesso em: 10 fev. 2020.

ARH CENTRO. Planos de Gestão de Bacia Hidrográfica dos rios Vouga, Mondego e Lis Integradas na Região Hidrográfica 4: Parte A - Avaliação Ambiental Estratégica. Coimbra, 2011, $205 \mathrm{p}$.

BARROS, A. M. L.; PAIVA, L. F. G.; CISNEIROS. S. J. N. Desafios da gestão dos usos múltiplos da água para atendimento energético ante a crise hídrica da bacia hidrográfica do Rio São Francisco - Operador Nacional do Sistema Elétrico (ONS). Bahia Análise de Dados, Salvador, v. 27, n. 1, p.258-278, 2017.

BOLSON, S. H.; HAONAT, A. I. A governança da água, a vulnerabilidade hídrica e os impactos das mudanças climáticas no Brasil. Veredas do Direito, Belo Horizonte, v. 13, n. 25, 2016. 
BRAGA, B. et al. Introdução à Engenharia Ambiental: o desafio do desenvolvimento sustentável. São Paulo: Pearson Prentice Hall, 2ª ed., 2005.

BRASIL. Código das Águas. Decreto no 24.643, de 10 de Julho de 1934. Disponível em: shttps://www.planalto.gov.br/ccivil 03/decreto/d24643.htm>. Acesso em: 8 jun. 2019.

. Ministério do Meio Ambiente dos Recursos Hídricos e da Amazônia Legal. Lei n. 9.433: Política Nacional de Recursos Hídricos. Brasília: Secretaria de Recursos Hídricos, 1997. 72p.

CALDAS, R. C. da S. G.; DIZ, J. B. M.; ANDREUCCI, A. G. A.; ACCIOLY, E. Gestão sustentável participativa transnacional: o direito de acesso a água potável, saneamento e sua governança global. Revista Opinião Jurídica, Fortaleza, ano 17, n. 25, 2019.

CAMPOS, V. N. de O.; LANZA, A. P. F. Governança das águas no Brasil: conflitos pela apropriação da água e a busca da integração como consenso. Ambiente \& Sociedade, Campinas. XIII, n. 2, 2010.

CASARIN, L. P. Avaliação da legislação vigente dos recursos hídricos no Brasil: um enfoque nas questões ecológicas. 2017. Trabalho de Conclusão de Curso - Universidade Estadual Paulista “Júlio de Mesquita Filho", Instituto de Biociências, Rio Claro, 2017.

CERQUEIRA, L. S.; FADUL, E.; VITÓRIA, F. T.; MORAIS, J. L. M. Produção científica em gestão de recursos hídricos no brasil no período de 2002 a 2011: uma análise da sua contribuição para o setor. Revista Gestão e Planejamento, Salvador, v. 17, n. 2, 2016.

COSTA, F. E. V. Gestão dos recursos hídricos na bacia hidrográfica do rio

Caeté/Pará/Brasil. 2017.Tese (Doutorado em Geografia). Universidade Estadual Paulista UNESP, São Paulo, 2017.

COSTA, F. S. et al. A legislação dos recursos hídricos em Portugal e no Brasil: uma análise histórica comparativa. Biblioteca da Universidade do Minho: Braga-Portugal, 2011. DERÍSIO, J. C. Introdução ao controle da poluição ambiental. São Paulo: Oficina de Textos, 5ㄹ Ed., 2017, 224 p.

FADUL, E.; VITÓRIA, F. T.; CERQUEIRA, L. S. Governança participativa na gestão de recursos hídricos no Brasil: uma análise da realidade do estado da Bahia. SINERGIA, Rio Grande, v. 21, n. 1, p.79-90, 2017.

FEIL, A. A.; STRASBURG, V. J.; SPILKI, F. R. Variáveis intervenientes na existência de comitês de bacias hidrográficas no Brasil. Ambiente \& Água: An Interdisciplinary Journal of Applied Science, Taubaté, v. 12, n. 2, 2017.

FERREIRA, C. Os hidroconflitos e a hidrodiplomacia na gestão das bacias hidrográficas internacionais. O caso ibérico. In: Actas do XVII Simpósio Brasileiro de Geografia Física: Os desafios da Geografia Física nas fronteiras do conhecimento, Campinas, pp. 7423-7427, 2017.

FERREIRA, S. M.; DEBEUS, G. Avaliação dos modelos de gestão ao longo da história em Portugal e Brasil: um olhar acerca das tendências internacionais nas políticas hídricas.

Revista Geografia em Atos, Presidente Prudente, v. 02, v. 09, 2018.

GIL, A. C. Métodos e técnicas de pesquisa social. São Paulo: Atlas, 7aㅡ Ed., 2019.

GUSMÃO, P. P.; PAVÃO, B. B. M. Gestão das águas, comitês de bacias hidrográficas e resolução de conflitos ambientais. Ambientes, v. 1, n. 2, 2019. 
IGARN. Instituto de Gestão das Águas do Estado do Rio Grande do Norte - IGARN. Dados oficiais 2017. Disponível em: http://www.igarn.rn.gov.br/. Acesso em: 10 fev. 2020.

INAG. Instituto da Água - INAG. Plano Nacional da Água, Lisboa: INAG, v. 1, 2001.

JACOBI, P. R. Governança da água no Brasil. In: RIBEIRO, W. C., Org. Governança da água no Brasil: uma visão interdisciplinar. São Paulo: Annablume; FAPESP; CNPq, 2009.

LOPES, M. M.; NEVES, F. F. A gestão de recursos hídricos no Brasil: um panorama geral dos estados. FACEF Pesquisa: Desenvolvimento e Gestão, v. 20, n. 3, 2017.

LUZ, J. P. A governança dos recursos hídricos no comitê de gerenciamento da bacia hidrográfica Taquari-Antas. 2017. Tese (Doutorado em Ambiente e Desenvolvimento), UNIVATES, Rio Grande do Sul, 2017.

MAGALHÃES JÚNIOR, A. P. Indicadores ambientais e recursos hídricos: realidade e perspectivas para o Brasil a partir da experiência francesa. $2^{\underline{a}}$ ed. Rio de Janeiro: Bertrand Brasil, 2010.

MAGALHÃES, S. C. M. et al. O gerenciamento das bacias hidrográficas no Brasil e em Portugal: um contributo atual. Biblioteca da Universidade do Minho: Braga-Portugal, 2011.

MARCONI, M. de A.; LAKATOS, E. M. Fundamentos de Metodologia Científica. São Paulo: Atlas, 8 $8^{\underline{a}}$ ed., 2017.

MARTINS, R. C. Fronteiras entre desigualdade e diferença na governança das águas. Ambiente \& Sociedade, Campinas v. XIII, n. 1, 2015.

MORANDI, M. I. W. M.; CAMARGO, L. F. R. Revisão sistemática da literatura. In: DRESCH, A.; LACERDA, D. P.; ANTUNES JR, J. A. V. Design sciencie research: método e pesquisa para avanço da ciência e da tecnologia. Porto Alegre: Bookman, 2015.

PARLAMENTO EUROPEU E O CONSELHO DA UNIÃO EUROPEIA. Directiva 2000/60/CE de 23 de Outubro de 2000. Jornal Oficial das Comunidades Europeias, Portugal, 22 dez. 2000. L 327/1.

PATO, J. H. O Valor da Água Como Bem Público. Tese (Doutoramento em Ciências Sociais) Instituto de Ciências Sociais, Universidade de Lisboa, Lisboa, 2007.

PORTUGAL. Decreto-Lei n.o 347 de 19 de outubro de 2007. Decreto-lei aprova a delimitação georreferenciada das regiões hidrográficas. Disponível em: https://dre.pt/. Acesso em: 10 jan. 2019.

PORTUGAL. Lei n. 44 de 19 de junho de 2017. Quinta alteração à Lei da Água, aprovada pela Lei $n . .58 / 2005$, de 29 de dezembro. Disponível em: https://dre.pt/. Acesso em: 10 jan. 2019.

PORTUGAL. Lei n.o 55 de 29 de dezembro de 2005. Lei da Água. Disponível em: https://dre.pt/.Acesso em: 10 jan. 2019.

PORTUGAL. Portaria n. -108 de 15 de março de 2013. A presente portaria aprova os estatutos da Agência Portuguesa do Ambiente. Disponível em: https://dre.pt/._Acesso em: 10 jan. 2019. 
PORTUGAL. Portaria n. 37 de 17 de fevereiro de 2015. A presente portaria procede à criação dos conselhos de região hidrográfica e regula o seu funcionamento. Disponível em: https://dre.pt/. Acesso em: 10 jan. 2019.

RIBEIRO, W. C. Impasses da governança da água no Brasil. In: RIBEIRO, W. C., Org. Governança da água no Brasil: uma visão interdisciplinar. São Paulo: Annablume; FAPESP; CNPq, 2009.

RIBEIRO, M. A. de F. M. Participação pública na gestão de recursos hídricos no Brasil e em Portugal. 2016. Tese (Doutorado em Recursos Naturais). Universidade Federal de Campina Grande - UFCG, Campina Grande, 2016.

RIBEIRO, M. A. de F. M.; RIBEIRO, M. M. R.; VARANDA, M. P. Public participation for bulk water charge: Paraíba River Basin Committee (Brazil) and Alentejo Hydrographic Region Council (Portugal) cases study. Revista Brasileira de Recursos Hídricos, Porto Alegre, v. 21, n. 4, 2016.

RIO GRANDE DO NORTE. Decreto Governamental no 21.881, de 10/09/2010. Comitê da Bacia Hidrográfica do Rio Apodi-Mossoró. Natal, 2009.

RIO GRANDE DO NORTE. Lei Estadual no 6.908, de 11 de julho de 1996, modificada pela Lei № 481 de 03 de janeiro de 2013. Política Estadual de Recursos Hídricos, institui o Sistema Integrado de Gestão de Recursos Hídricos - SIGERH. Natal, 2013.

SCHIMDT, L.; FERREIRA, J. G. A governança da água no contexto de aplicação da directiva quadro da água. Instituto de Ciências Sociais, Universidade de Lisboa, Lisboa, 2013.

SEMARH. Secretaria de Meio Ambiente e Recursos Hídricos - SEMARH. Dados oficiais 2020. Disponível em: http://www.semarh.rn.gov.br/. Acesso em: 10 fev. 2020.

SILVA, A. R. da. et al. A gestão e monitoramento das águas: uma abordagem das legislações em Portugal e no Brasil. Revista Brasileira de Geografia Física, v.11, n.04, 2018.

SILVA, M. B.; HERRERO, M. M. A. G.; BORGES, F. Q. Gestão integrada dos recursos hídricos como política de gerenciamento das águas no Brasil. Revista de Administração da Universidade Federal de Santa Maria, Santa Maria, v. 10, n. 1, 2017.

SILVA, S. C.; FERREIRA, T.; POMPEO, M. L. M. Diretiva quadro d'água: uma revisão crítica e a possibilidade de aplicação ao brasil. Ambiente \& Sociedade, São Paulo v. XVI, n. 1, 2013.

TRAVASSOS, N. L. M. A gestão dos recursos hídricos frente aos desafios de efetivação da legislação ambiental: uma abordagem comparativa entre Portugal e Brasil. 2013. Dissertação (Mestrado em Ciências e Tecnologia do Ambiente). Universidade do Porto, Porto, 2013.

TRINDADE, L. de L.; SCHEIBE, L. F.; RIBEIRO, W. C. A governança da água: o caso dos comitês dos rios Chapecó e Irani-SC. Geosul, Florianópolis, v. 33, n. 68, p. 36-57, 2018.

TONELOTTO, D. P.; C. J. Endividamento público em nível local: estudo comparativo da legislação entre Brasil e Portugal. Revista Gestão e Políticas Públicas, v. 6, n. 2, 2017.

TUNDISI, J. G. Recursos hídricos no Século XXI. São Paulo: Oficina de Textos, $2^{a}$ ed., 2011. 
TUNDISI, J. G. Governança da água. Revista da Universidade Federal de Minas Gerais, v. 20, n. $2,2016$.

VASCONCELOS, D. et al. Governança da água no Brasil: uma contribuição bibliométrica. Revista HOLOS, Natal, a. 32, v. 08, 2016.

VASCONCELOS, L. Ecossistemas, Água e Participação: estratégias nas políticas de recursos hídricos do Portugal, Brasil e Moçambique. Revista Online da Sociedade Portuguesa de Ecologia, Lisboa, v. 2, 2011.

YIN. R. K. Estudo de caso: planejamento e métodos. Porto Alegre: Bookman, 3ª ed., 2005.

YOUNG, J.; SEDOURA, F. M. Planos diretores municipais e planos de gestão das águas: uma análise comparada das cidades de Lisboa/PT e Porto Alegre/BR. Urbe: Revista Brasileira de Gestão Urbana, Curitiba, v. 11, 2019.

ZUCCO, E.; COSTA, F. S. O planeamento dos recursos hídricos em Portugal e o Segundo ciclo dos Planos de gestão de bacia hidrográfica. In: A JANGADA DE PEDRA - Geografias Ibero-Afro-Americanas, Atas do XIV Colóquio I.

\section{NOTAS DE AUTOR}

\section{CONTRIBUIÇÃO DE AUTORIA}

Jorge Luís de Oliveira Pinto Filho - Concepção. Coleta de dados, Análise de dados, Elaboração do manuscrito, revisão e aprovação da versão final do trabalho

Lucio Cunha - Participação ativa da discussão dos resultados; Revisão e aprovação da versão final do trabalho.

\section{FINANCIAMENTO}

Financiamento Interno da Universidade Federal Rural do Semi-Árido - UFERSA

Financiamento Interno da Universidade de Coimbra - UC

\section{CONSENTIMENTO DE USO DE IMAGEM}

Não se aplica

\section{APROVAÇÃO DE COMITÊ DE ÉTICA EM PESQUISA}

Não se aplica.

\section{CONFLITO DE INTERESSES}

Informar conflitos de interesse: financeiros, pessoais, entre possíveis revisores e editores, possíveis vieses temáticos. Para mais informações: https://www.abecbrasil.org.br/arquivos/whitepaper_CSE.pdf

\section{LICENÇA DE USO}

Este artigo está licenciado sob a Licença Creative Commons CC-BY. Com essa licença você pode compartilhar, adaptar, criar para qualquer fim, desde que atribua a autoria da obra.

\section{HISTÓRICO}

Recebido em: 17-04-2020

Aprovado em: 22-09-2020 